\title{
BIOMIMETIC MODIFICATION OF SYNTHETIC HYDROGELS BY INCORPORATION OF ADHESIVE PEPTIDES AND CALCIUM PHOSPHATE NANOPARTICLES: IN VITRO EVALUATION OF CELL BEHAVIOR
}

\author{
M. Bongio ${ }^{1}$, J.J.J.P. van den Beucken ${ }^{1}$, M.R. Nejadnik¹, S.C.G. Leeuwenburgh ${ }^{1}$, L.A. Kinard ${ }^{2}$, F.K. Kasper ${ }^{3}$, \\ A.G. Mikos $^{2,3}$ and J.A. Jansen ${ }^{1, *}$ \\ ${ }^{1}$ Department of Biomaterials, Radboud University Nijmegen Medical Centre, Nijmegen, the Netherlands \\ ${ }^{2}$ Department of Chemical and Biomolecular Engineering, Rice University, Houston, Texas, USA \\ ${ }^{3}$ Department of Bioengineering, Rice University, Houston, Texas, USA
}

\begin{abstract}
The ultimate goal of this work was to develop a biocompatible and biomimetic in situ crosslinkable hydrogel scaffold with an instructive capacity for bone regenerative treatment. To this end, synthetic hydrogels were functionalized with two key components of the extracellular matrix of native bone tissue, i.e. the three-amino acid peptide sequence RGD (which is the principal integrin-binding domain responsible for cell adhesion and survival of anchorage-dependent cells) and calcium phosphate $(\mathrm{CaP})$ nanoparticles in the form of hydroxyapatite (which are similar to the inorganic phase of bone tissue). Rat bone marrow osteoblast-like cells (OBLCs) were encapsulated in four different biomaterials (plain oligo(poly(ethylene glycol) fumarate) (OPF), RGDmodified OPF, OPF enriched with CaP nanoparticles and RGD-modified OPF enriched with CaP nanoparticles) and cell survival, cell spreading, proliferation and mineralized matrix formation were determined via cell viability assay, histology and biochemical analysis for alkaline phosphatase activity and calcium. This study showed that RGD peptide sequences promoted cell spreading in OPF hydrogels and hence play a crucial role in cell survival during the early stage of culture, whereas CaP nanoparticles significantly enhanced cell-mediated hydrogel mineralization. Although cell spreading and proliferation activity were inhibited, the combined effect of RGD peptide sequences and $\mathrm{CaP}$ nanoparticles within OPF hydrogel systems elicited a better biological response than that of the individual components. Specifically, both a sustained cell viability and mineralized matrix production mediated by encapsulated OBLCs were observed within these novel biomimetic composite systems.
\end{abstract}

Keywords: Synthetic polymers, biomimetic hydrogels, RGD peptide, calcium phosphate nanoparticles, cellmaterial interactions, in vitro mineralization.

\author{
*Address for correspondence: \\ John A Jansen, DDS, PhD \\ Radboud University Nijmegen Medical Center \\ Department of Biomaterials (309) \\ PO Box 9101 \\ 6500 HB Nijmegen \\ The Netherlands
}

Phone: +31-24-3614006

Fax: $+31-24-3614657$

E-mail: j.jansen@dent.umcn.nl

Web:www.biomaterials-umcn.nl

\section{Introduction}

Over the last decades, a more refined understanding of the biological properties relevant to bone substitute materials encouraged the scientific community to develop increasingly powerful scaffolds that are able to tolerate and support the damaged tissue, to interact with the physiological environment, and even to guide new bone formation (Bongio et al., 2010). Among these, hydrogels are currently being broadly explored for bone tissue engineering applications. Hydrogels are hydrophilic networks of synthetic or natural polymer chains that can approximate the viscoelastic properties of native tissue (Peppas et al., 2006). Due to these and other distinctive features, such as biocompatibility, biodegradability, injectability and ability to release entrapped drugs, these polymeric hydrogels are generally recognized as highly attractive candidates for use in rengenerative medicine.

Oligo(poly(ethylene glycol) fumarate) (OPF) hydrogels have been explored as synthetic matrices for bone and cartilage tissue engineering applications (Guo et al., 2010; Park et al., 2005; Park et al., 2007; Temenoff et al., 2004b). OPF polymers consist of two repeating units, poly(ethylene glycol) (PEG) and fumaric acid, which are alternately linked by ester bonds and can be degraded in aqueous solutions (Shin et al., 2003). Although many advantages for this material exist, including versatile swelling characteristics and tailorable structural as well as mechanical properties (Brink et al., 2009; Guo et al., 2010; Holland et al., 2003; Holland et al., 2005; Jo et al., 2001b; Temenoff et al., 2002; Temenoff et al., 2004a), the purely synthetic components of OPF do not possess biospecific cell adhesion sites, which limits cell-material interactions and potentially leads to anoikis (i.e., cell death due to lack of matrix interactions) of anchorage-dependent cells (Salinas and Anseth, 2009). To overcome such a drawback, biomimetic approaches have been developed to functionalize synthetic matrices with bioactive molecules, such as growth factors or adhesive peptide sequences. Over the past decades, the tri-amino acid sequence RGD (arginine-glycine-aspartic acid) has been identified to be the principal integrin-binding domain present within adhesive proteins of the extracellular matrix (ECM), including fibronectin, vitronectin, fibrinogen and osteopontin (Barczyk et al., 2010; Pierschbacher and Ruoslahti, 1984). More recently, immobilization of "pro-adhesive" ligands on cell repellent surfaces has been shown to be pivotal in the interaction with neighboring cells and regulation of cell functions associated with regeneration of lost or damaged tissues (Bellis, 2011). 
Shin and co-workers have already shown the potential of RGD peptides tethered to OPF-based hydrogels to improve cell adhesion and hence to control cell-functions. More specifically, cell migration, osteogenic differentiation and mineralization were modulated by varying either the tether peptide concentration or the nature of the peptide sequence (Shin et al., 2002; Shin et al., 2004b; Shin et al., 2004a).

Taking inspiration from the mineral component and nanostructure of natural bone, which itself is a nanocomposite, we have previously combined OPF hydrogels with calcium phosphate $(\mathrm{CaP})$ in the form of carbonated apatite nanocrystals (Leeuwenburgh et al., 2007). The major advantage for developing a composite material is the possibility of combining multiple properties associated with the natural tissue. While the polymeric network resembles the architecture of natural ECM, and hence acts as a supportive environment for cell functions (Drury and Mooney, 2003), homogeneously dispersed $\mathrm{CaP}$ nanoparticles render the resulting composite osteoconductive, encourage protein adsorption (Kilpadi et $a l ., 2001)$ and increase matrix stiffness, thereby exerting strong effects on lineage specification and commitment of naive mesenchymal stem cells (Engler et al., 2006).

To date, only few attempts to design a biomimetic hydrogel by means of combining adhesive peptides and nanosized $\mathrm{CaP}$ particles to elicit an osteogenic response from precursor cells have been reported (Paxton et al., 2009; Xu et al., 2010). The overall objective of the present study was to assess the biological behavior of encapsulated bone marrow derived osteoblast-like cells (OBLCs) within a novel three-dimensional (3D) OPF-based hydrogel system in vitro. Experimental groups consisted of OPF hydrogels either modified with GRGD (glycine-arginineglycine-aspartic acid), CaP nanoparticles or a combination thereof (Fig. 1a,b). Specific objectives of this study were (1) to assess whether GRGD peptides affect cell spreading and hence cell viability, (2) to investigate the role of $\mathrm{CaP}$ nanoparticles in potential biomimetic mineralization of OPF-based hydrogels, thus stimulating encapsulated OBLCs to mineralize their environment, and finally, (3) to evaluate the potential combined effect between tethered GRGD peptides and CaP nanoparticles on the overall biological performance of the scaffolds compared to plain OPF, with the ultimate goal of developing biomimetic composite systems for bone tissue engineering.

\section{Materials and Methods}

\section{Reagents and culture supplements}

Fumaryl chloride, phosphoric acid $\left(\mathrm{H}_{3} \mathrm{PO}_{4}\right)$ and calcium hydroxide $\left(\mathrm{Ca}(\mathrm{OH})_{2}\right)$ were obtained from Acros (Pittsburgh, PA, USA). Poly(ethylene glycol) (PEG) was purchased from Aldrich (Milwaukee, WI, USA). Poly(ethylene glycol) diacrylate (PEGDA, MW $3400 \mathrm{Da}$ ) was purchased by Glycosan Biosystems (Salt Lake City, UT, USA). GRGD peptide (MW 403.40 Da) was obtained from Bachem (Torrance, CA, USA). Acrylate-PEG-succinimidyl carboxymethyl (acrylate-PEG-SCM; MW 3400 Da) was purchased from Laysan Bio (Arab, AL, USA). $N, N, N^{\prime}, N^{\prime}$ tetramethylethylenediamine (TEMED) was obtained from Fluka (Buchs, Switzerland). Ammonium persulfate (APS), ninhydrin reagent, phosphate-buffered saline, $\mathrm{pH} 7.4$ (PBS), Dulbecco's modified Eagle medium (DMEM), fetal bovine serum (FBS), dexamethasone, $\beta$-glycerophosphate, ascorbic acid, fungizone, ampicillin, gentamicin, trypsinEDTA, and $10 \%$ neutral-buffered formalin were purchased from Sigma-Aldrich (St. Louis, MO, USA).

\section{OPF synthesis}

OPF macromer was synthesized using fumaryl chloride and poly(ethylene glycol) (PEG) with an initial molecular weight of $10,000 \mathrm{~g} / \mathrm{mol}$ (designated OPF $10 \mathrm{~K}$ ), following established procedures (Jo et al., 2001b). The purified macromer was stored at $-20{ }^{\circ} \mathrm{C}$.

\section{Synthesis of acrylate-PEG-peptide conjugates}

Synthesis of acrylated peptide was conducted by reacting GRGD peptide with acrylate-PEG-SCM, as previously described (Hern and Hubbell, 1998). Specifically, the peptide was dissolved to a final aqueous concentration of 1 $\mathrm{mg} / \mathrm{mL}$ in $50 \mathrm{mM}$ sodium bicarbonate buffer, $\mathrm{pH}$ 8.2. The acrylate-PEG-SCM was dissolved separately in $50 \mathrm{mM}$ of bicarbonate buffer in a scintillation vial, such that the final molar ratio of acrylate-PEG-SCM to peptide was 2 . The PEG solution $(2 \mathrm{~mL})$ was added dropwise to the peptide solution $(10 \mathrm{~mL})$ using a syringe pump positioned on a magnetic stir plate over $20 \mathrm{~min}(0.1 \mathrm{~mL} / \mathrm{min})$. The solution was reacted at room temperature for $2.5 \mathrm{~h}$ and dialyzed using 2000 MWCO dialysis membranes (Slide-A-Lyzer Dialysis cassette, Thermo Scientific) for $2 \mathrm{~d}$ using distilled deionized water with periodic changes. The primary goal of purification was the removal of non-acrylated peptide. The final dialysis product was frozen in liquid nitrogen and lyophilized to remove water for $48 \mathrm{~h}$, then stored at $-20{ }^{\circ} \mathrm{C}$ until use.

\section{Characterization of acrylate-PEG-peptide conjugates} The efficiency of peptide conjugation was determined by the ninhydrin assay according to the manufacturer's instructions. Briefly, working solution was freshly prepared on the day of the assay by adding $4 \mathrm{M}$ lithium acetate buffer $(4.5 \mathrm{~mL})$ in ninhydrin reagent solution (13.5 $\mathrm{mL}$ ) and stirring under a nitrogen purge for $10 \mathrm{~min}$. Five standards (range: $0-0.033 \mu \mathrm{mol} / \mathrm{mL}$ ) were prepared in 1.5 $\mathrm{mL}$ tubes from a stock solution of GRGD at a concentration of $0.05 \mu \mathrm{mol} / \mathrm{mL}(50 \mu \mathrm{M})$ in $0.05 \%$ glacial acetic acid. Standards and samples (acrylated PEG-GRGD pre-dialysis and acrylated PEG-GRGD post-dialysis) were added to MilliQ $\mathrm{H}_{2} \mathrm{O}$ and ninhydrin reagent (final volume $2 \mathrm{~mL}$ ) in $15 \mathrm{~mL}$ tubes. The tubes were immediately capped, gently mixed and heated in boiling water for $10 \mathrm{~min}$ to allow the reaction to proceed. After cooling, $5 \mathrm{~mL}$ of $95 \%$ ethanol was added to each tube. Samples and standards $(300 \mu \mathrm{L})$ were transferred to a 96-well plate and run in triplicate. The absorbance of each solution was measured on a UV spectrophotometer at $570 \mathrm{~nm}$, and the concentration of free GRGD peptide in the samples was calculated from the standard calibration curve. 
Table 1. Compounds and relative amounts used to prepare OPF hydrogel scaffolds.

\begin{tabular}{l|cccc} 
& \multicolumn{4}{c}{ SCAFFOLDS } \\
\hline OPF $(\mathrm{g})$ & OPF & OPF-R & OPF-CaP & OPF-R-CaP \\
\hline PEGDA $(\mathrm{g})$ & 0.15 & 0.15 & 0.15 & 0.15 \\
\hline PEG-R $(\mathrm{g})$ & 0.075 & 0.066 & 0.075 & 0.066 \\
\hline PBS $(\mu \mathrm{L})$ & - & 0.018 & - & 0.018 \\
\hline CaP suspension $(\mu \mathrm{L})$ & 692 & 692 & - & - \\
\hline 0.3 M APS $(\mu \mathrm{L})$ & - & - & 692 & 692 \\
\hline 0.3 M TEMED $(\mu \mathrm{L})$ & 70 & 70 & 70 & 70 \\
\hline Cell suspension*/culture medium** $(\mu \mathrm{L})$ & 168 & 168 & 168 & 70 \\
\hline Total volume $(\mu \mathrm{L})$ & 1000 & 1000 & 1000 & 1000 \\
$*$ Cell-laden hydrogels & 70 & 70 & & \\
$* *$ Cell-free hydrogels & & & &
\end{tabular}

\section{CaP nanoparticles preparation}

Stable suspensions of homogeneously dispersed needle-like apatite nanoparticles were prepared using a conventional wet-chemical precipitation method. Specifically, $25 \mathrm{~mL}$ of a solution of $\mathrm{H}_{3} \mathrm{PO}_{4}(3.56 \mathrm{M})$ was added dropwise at a rate of about 1-2 drops per second into $25 \mathrm{~mL}$ of a basic suspension of $\mathrm{Ca}(\mathrm{OH})_{2}(5.92 \mathrm{M})$, while stirring at a temperature of 60 ${ }^{\circ} \mathrm{C}$. The amounts of reagents were used at a stoichiometric $\mathrm{Ca} / \mathrm{P}$ ratio of 1.67 to obtain an apatite content of $\sim 0.3 \mathrm{~g} / \mathrm{mL}$ $(\mathrm{CaP} 30 \% \mathrm{w} / \mathrm{v})$. The product was left to age for $15-18 \mathrm{~h}$. After aging, the $\mathrm{pH}$ of the suspensions was adjusted to 7.4 and then autoclaved for sterilization. Since the aim of this study was to maximize the amount of $\mathrm{CaP}$ nanoparticles in the hydrogel composite, the $\mathrm{CaP}$ content was also maximized in the suspension up to a value of $30 \% \mathrm{w} / \mathrm{v}$. At higher $\mathrm{CaP}$ contents, stable and homogeneous suspensions could not be obtained anymore using the described reaction.

\section{Characterization of CaP nanoparticles}

Prior to characterization, the prepared $\mathrm{CaP}$ nanoparticles were washed with ultrapure water in three subsequent series of centrifugation and rinsing steps. Subsequently, the nanoparticles were dried for X-ray diffraction analysis (XRD, Philips, PW 1830, Almelo, the Netherlands) and attenuated total reflection-Fourier transform infrared spectroscopy (ATR-FTIR, Perkin Elmer, Spectrum One, Groningen, the Netherlands). Specifically, XRD was performed in a reflection geometry using a $\mathrm{Cu} \mathrm{K} \alpha$ radiation source $(1.54056 \AA)$ at a voltage of $40 \mathrm{kV}$ and a current of 30 $\mathrm{mA}$. Spectra were collected at a scanning rate of $0.01 \%$ in the $2 \Theta$ range of $20^{\circ}$ to $60^{\circ}\left(0.02^{\circ}\right.$ interval $)$. ATR-FTIR was performed in the range of 500 to $2000 \mathrm{~cm}^{-1}$ at $22{ }^{\circ} \mathrm{C}$. To record spectra with satisfying peak-to-noise ratio, 10 scans were averaged for each sample. Finally, transmission electron microscopy (TEM, Jeol, JEM 1010, Tokyo, Japan) was used to image the $\mathrm{CaP}$ nanoparticles at an acceleration voltage of $60 \mathrm{kV}$. In order to prepare samples for TEM, a drop of $\mathrm{CaP}$ suspension was deposited onto a TEM grid and left to dry in air.
Bone marrow stromal cell isolation and preculture Primary cells were freshly isolated from 8 Fischer 344 male rats (6-8 weeks old, 150-165 g), as previously described (Peter et al., 2000). Briefly, femora and tibiae were excised from the rats under aseptic conditions, and the bone marrow was flushed from the bone with primary media. Freshly isolated cells from two femora and two tibiae were seeded in three T-75 culture flasks. The cells were precultured for $6 \mathrm{~d}$ in DMEM supplemented with $10 \% \mathrm{v} / \mathrm{v}$ FBS, $10^{-8} \mathrm{M}$ dexamethasone, $10 \mathrm{mM} \beta$-glycerophosphate, $50 \mathrm{mg} / \mathrm{L}$ ascorbic acid, $250 \mu \mathrm{g} / \mathrm{L}$ fungizone, $100 \mathrm{mg} / \mathrm{L}$ ampicillin, and $50 \mathrm{mg} / \mathrm{L}$ gentamicin, at $37{ }^{\circ} \mathrm{C}, 95 \%$ relative humidity and $5 \% \mathrm{CO}_{2}$ to obtain osteoblast-like cells (OBLCs). Non-adherent cells were removed and the media were refreshed three times per week. After $6 \mathrm{~d}$, the OBLCs were washed twice with PBS, enzymatically lifted with exposure to $0.25 \%$ trypsin-EDTA for $5 \mathrm{~min}$, and resuspended in osteogenic medium.

\section{OBLCs encapsulation and culture}

OPF, PEGDA and acrylated-PEG-GRGD (PEG-R) were sterilized by exposure to ethylene oxide for $14 \mathrm{~h}$ and physically mixed as outlined in Table 1 . Hydrogels were fabricated using $2 \mu \mathrm{mol}$ of PEG-R per $\mathrm{mL}$ of precursor solution. This concentration was demonstrated to be optimal for cell proliferation, alkaline phosphatase (ALP) activity and mineralized matrix formation in previous studies (Shin et al., 2005; Shin et al., 2004b). The approximate ratio of the double bonds in PEGDA or PEGDA plus PEG-R to those in OPF was 6. Subsequently, either sterile PBS (for CaP-free hydrogels) or $\mathrm{CaP}$ suspension (for $\mathrm{CaP}$ enriched hydrogels) was added to the polymers, and the mixtures were shaken at room temperature for $30 \mathrm{~min}$. The polymer/CaP ratio was calculated to be $50 / 50 \mathrm{w} / \mathrm{w}$. Equal volumes of sterile initiator solutions, $300 \mathrm{mM}$ APS and $300 \mathrm{mM}$ TEMED, were added. Next, 10 million cells/ $\mathrm{mL}$ were added to the OPF solution to prepare cell-laden hydrogels. After gentle mixing, $30 \mu \mathrm{L}$ of the polymer mixture (containing 300,000 cells) was quickly injected 
in pre-sterilized Teflon molds, followed by incubation at $37^{\circ} \mathrm{C}$ for $30 \mathrm{~min}$. Previous studies indicated that RGD is successfully incorporated into the gel network using the described method (Jo et al., 2001a; Shin et al., 2005). The newly formed cross-linked gels were transferred to 24 -well plates. $2 \mathrm{~mL}$ of medium including osteogenic supplements was added and changed $1 \mathrm{~h}$ and $1 \mathrm{~d}$ after encapsulation to ensure the removal of unreacted components. During the culture period, the medium was changed three times per week to prevent nutrient exhaustion. Constructs were collected after 4, 8, 12, 16 and $24 \mathrm{~d}$ in culture following initial seeding. In addition, scaffolds without cells were made as described above, except for the fact that culture medium was added instead of the cell suspension. These cell-free hydrogels, soaked in complete osteogenic medium, were subjected to the same analyses as cell-laden hydrogels in order to be used as background value (blank) and to evaluate the cell-mediated calcium accumulation in cellular gels compared to the passive mineralization in acellular gels.

\section{Hydrogel composite characterization}

Cell-free hydrogels from OPF and OPF-CaP groups $(n=$ 3 ) were used for material characterization analyses. First, the hydrated samples were subjected to rheological studies using an AR2000ex rheometer (TA Instrument, New Castle, NJ, USA) equipped with a flat, steel-plate geometry (20 $\mathrm{mm}$ diameter) at $22{ }^{\circ} \mathrm{C}$. Storage modulus $\left(\mathrm{G}^{\prime}\right)$ and loss modulus $\left(\mathrm{G}^{\prime \prime}\right)$ were determined employing an oscillatory time sweep test for $10 \mathrm{~min}$ at a constant strain of $1 \%$ and constant frequency of $1 \mathrm{~Hz}$. Analyses of the results revealed that the effects of the evaporation on measurements were negligible given the low temperature and short duration of the experiment.

In addition, samples were freeze-dried (for $48 \mathrm{~h}$ ) and coated with a thin gold layer for Field Emission Scanning Electron Microscopy (FESEM, Jeol6330, Tokyo, Japan) performed at $5 \mathrm{kV}$. Separate samples were used to collect ATR-FTIR spectra. Furthermore, the fold swelling ratios of the hydrogels (swollen in MilliQ $\mathrm{H}_{2} \mathrm{O}$ overnight) were calculated according to the following formula:

$$
\text { Fold swelling }=(\mathrm{Ws}-\mathrm{Wd}) / \mathrm{Wd}
$$

Ws and Wd are the weight of the disc in swollen and dry (i.e. lyophilized) states, respectively.

\section{Cell survival}

Cell survival was determined using a LIVE/DEAD Viability/Cytotoxicity Kit (Molecular Probes, Eugene, OR, USA), which measures the membrane integrity of cells. Constructs were washed in sterile PBS for $30 \mathrm{~min}$ at $37^{\circ} \mathrm{C}$ prior to incubation for $30 \mathrm{~min}$ at room temperature with $2 \mathrm{mM}$ calcein-AM and $4 \mathrm{mM}$ ethidium homodimer in PBS solution. After incubation, constructs were rinsed again in PBS for confocal microscopy. Cell viability was assessed after 4 and $16 \mathrm{~d}$ of culture. Percentage of live cells was quantified using Image $\mathrm{J}$ software (Zeiss LSM Image Browser, Version 4.2.0.121, Jena, Germany) for a minimum of four images from two samples for each condition.

\section{Cell behavior}

At days 4, 8, 12, 16 and 24, samples and blanks were washed in PBS for $30 \mathrm{~min}$ at $37^{\circ} \mathrm{C}$ and homogenized with a pellet grinder (Kontes Pellet Pestle, Daigger, Vernon Hills, IL, USA) in $1000 \mu \mathrm{L}$ double distilled water. The samples were frozen at $-20^{\circ} \mathrm{C}$ before analysis. At the time of analyses, samples were subjected to three freeze-thaw cycles including sonication with ice for $10 \mathrm{~min}$ after each cycle. A total of $n=3$ replicates per time point for each experimental condition were used.

\section{Proliferation}

Double-stranded DNA content from all homogenates at each time point was measured using a fluorometric PicoGreen DNA kit (Molecular Probes, Junction City, KS, USA) following the protocol of the manufacturer. Briefly, $100 \mu \mathrm{L}$ of samples or DNA standards were incubated with $100 \mu \mathrm{L}$ of PicoGreen working solution and allowed to incubate at room temperature for $10 \mathrm{~min}$ in the dark. The excitation of the solution at $485 \mathrm{~nm}$ and fluorescence measurement at $530 \mathrm{~nm}$ was performed using a FLx800 fluorescence microplate reader (Bio-Tek Instruments, Winooski, VT, USA). The values of cell-free hydrogels were subtracted from the sample values of corresponding cell-laden hydrogels.

\section{Differentiation}

ALP activity was measured by using Sigma diagnostic kit 104 , according to instructions of the manufacturer. Briefly, $80 \mu \mathrm{L}$ of sample and $20 \mu \mathrm{L}$ of alkaline buffer were added to $100 \mu \mathrm{L}$ of substrate solution $(5 \mathrm{mM}$ paranitrophenyl phosphate). A standard curve was made (range: 0-25 nmol/ $\mathrm{mL}$ ) of the stock solution (4-nitrophenol). Samples and standards were added to a 96-well plate and incubated at 37 ${ }^{\circ} \mathrm{C}$ for $60 \mathrm{~min}$. The reaction was terminated by the addition of $100 \mu \mathrm{L}$ of $0.3 \mathrm{M} \mathrm{NaOH}$ to each well. The absorbance of each well was read at $405 \mathrm{~nm}$ using a PowerWave X340 microplate spectrophotometer (Bio-Tek Instruments, Winooski, VT, USA). Absorbance of the samples was adjusted with cell-free hydrogels and the values were normalized to the amount of DNA.

\section{Mineralization}

Before analysis of calcium content for each homogenate, $1.0 \mathrm{~N}$ acetic acid was added to the samples and placed on a shaker table overnight to dissolve mineral deposits. A volume of $20 \mu \mathrm{L}$ samples or standards were incubated with $300 \mu \mathrm{L}$ of working solution (Genzyme Diagnostics, Cambridge, MA, USA). The standards (range: 0-100 $\mu \mathrm{g} /$ $\mathrm{mL}$ ) were prepared using a $\mathrm{CaCl}_{2}$ stock solution. The absorbance of each well was measured at $570 \mathrm{~nm}$ on a PowerWave X340 microplate spectrophotometer (Bio-Tek Instruments). The readout values of cell-containing gels were compensated for the calcium uptake as measured for cell-free hydrogels.

\section{Cytological Analysis}

Two specimens $(n=2)$ for each group at day 4,16 and 24 were fixed in $10 \%$ neutral-buffered formalin, serially dehydrated in ethanol (35\% and $70 \%$ ), paraffin-embedded, and cut on a microtome in $6 \mu \mathrm{m}$-thick cross sections. The 

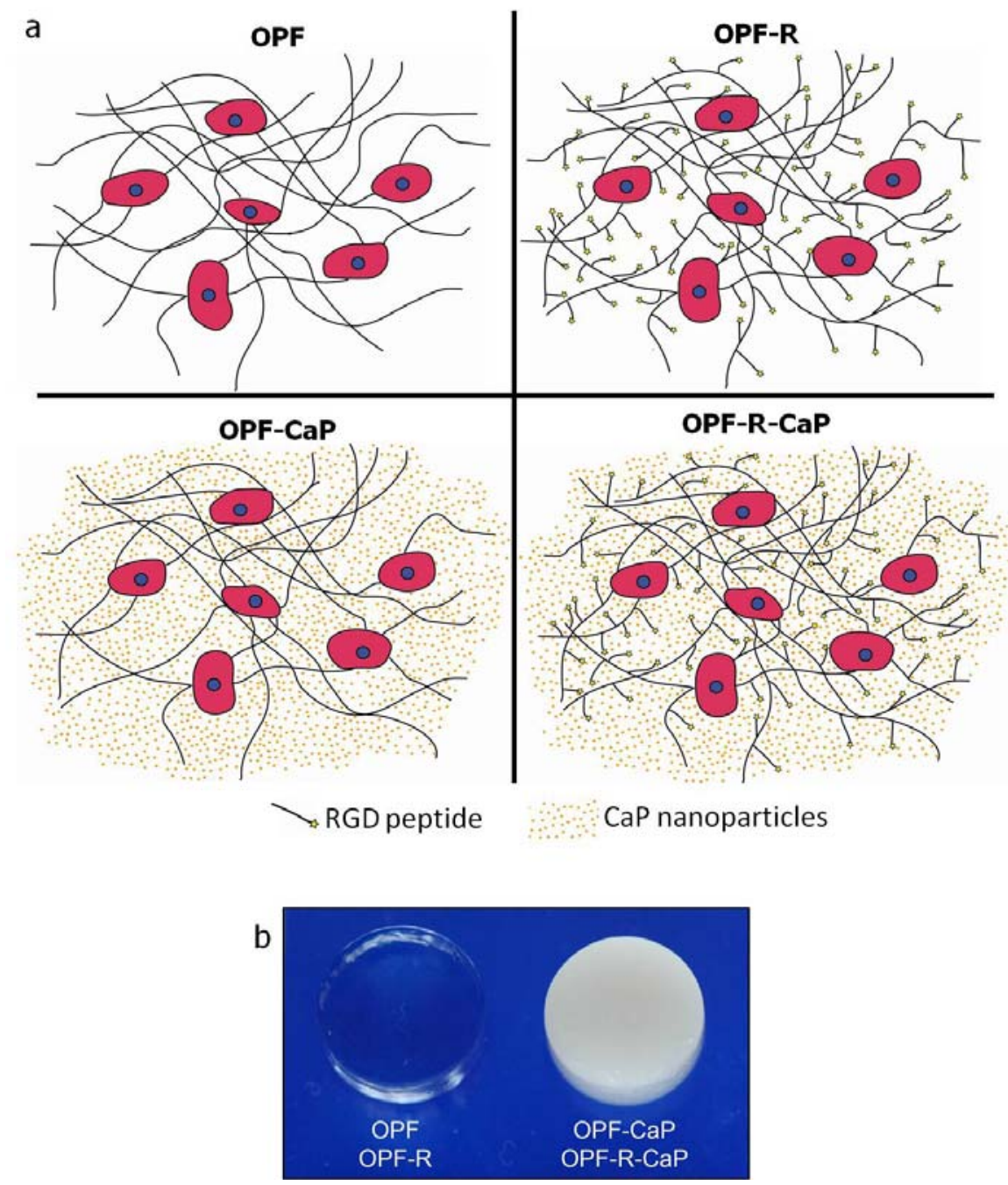

Fig. 1. (a) Schematic drawing of OBLCs encapsulated in OPF hydrogels involved in this study, and (b) representative images of CaP-free (OPF and OPF-R) and CaP-enriched (OPF-CaP and OPF-R-CaP) hydrogels.

sections were subsequently mounted on glass slides and stained with Von Kossa reagent to visualize the mineralized matrix and counterstained with Nuclear Fast Red. The resulting slides were imaged with a light microscope (Axio Imager Microscope Z1, Carl Zeiss Micro imaging $\mathrm{GmbH}$, Göttingen, Germany) equipped with a digital camera.

\section{Roundness}

Roundness index was used to evaluate cell spreading of encapsulated cells, according to a previously described method (Kim et al., 2010). The analysis was based on Von Kossa-stained histological sections (2 specimens per experimental group, 2 histological sections per specimen, 3 views per histological section) at day 4, 16 and 24. A minimum number of 50 cells were counted per histological section. The roundness of cells was computed (Leica Qwin Pro-image analysis software; Leica imaging system, Cambrige, UK) by the formula:

$$
\text { Roundness index }=\text { Perimeter }^{2} / 4 \times \pi \times \text { Area } \times 1.064
$$

Perimeter is the total length of the boundary of the cell and Area is the total number of pixels within the cell. The adjustment factor of 1.064 corrects the parameter for the effect of the corners produced by the digitization of the image. This equation gives a minimum value of 1 for a true circle. Therefore, the roundness index of a cell with less cellular extensions is closer to 1 . On the contrary, the cells with more cellular extensions have a roundness greater than 1 .

\section{Statistical analysis}

Analysis of quantitative data consisted of one way ANOVA combined with a post-hoc Tukey-Kramer Multiple Comparisons Test to detect statistically significant differences at a significance level (or $p$-value) of $p<0.05$. Results are reported as means \pm standard deviations.

\section{Results}

To test the reproducibility, the entire experiment was performed for two independent runs with a separate isolation of pooled cells for each run. Both experimental runs showed similar results. 

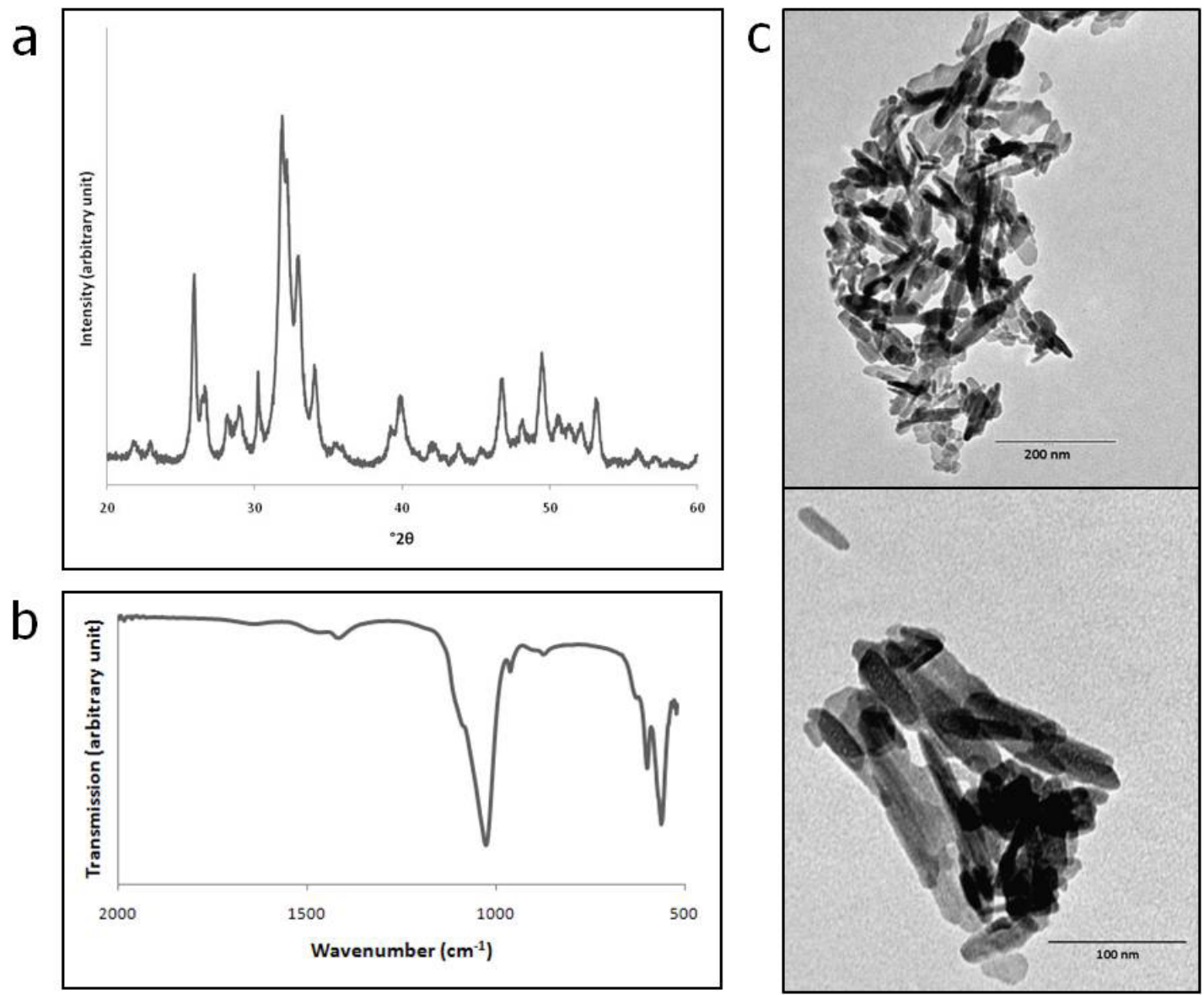

b

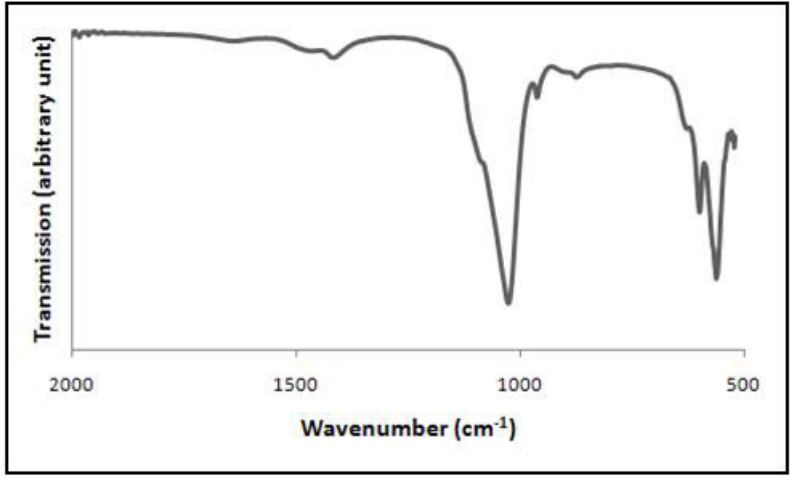

Fig. 2. (a) XRD analysis, (b) ATR-FTIR analysis, and (c) representative TEM images of CaP nanoparticles.

For ease of understanding, in the following text, the groups used in this study will be referred to as OPF (plain hydrogel), OPF-R (RGD-modified OPF hydrogel), OPF-CaP (OPF hydrogel with incorporation of $\mathrm{CaP}$ nanoparticles), and OPF-R-CaP (RGD-modified OPF hydrogel with incorporation of $\mathrm{CaP}$ nanoparticles), as reported in Table 1.

\section{Material characterization}

Spectroscopic analysis using ninhydrin reagents demonstrated that the acrylation efficiency of PEG-GRGD obtained was $85 \%$ and reproducible for both experimental runs.

XRD analysis showed that the prepared CaP nanoparticles were crystalline as revealed by main reflection peaks for apatite (at $25.9^{\circ}$ and $31.8^{\circ}$ ) and minor traces of monetite as a secondary CaP phase (at $26.7^{\circ}$ and $30.2^{\circ}$ ) (Fig. 2a). Complementing ATR-FTIR analyses (Fig. b) confirmed the presence of apatitic phosphate by clear absorption peaks at 563, 600, 963 and $1027 \mathrm{~cm}^{-1}$ and a hydroxyl absorption peak at $628 \mathrm{~cm}^{-1}$. TEM images (Fig. 2c) showed needle-shaped nanoparticles with average diameter and length of $18 \pm 7$ and $76 \pm 23 \mathrm{~nm}$, respectively.

Viscoelastic properties of OPF and OPF-CaP hydrogels were significantly different, as shown in Fig. 3. Specifically, OPF-CaP yielded a storage modulus $\left(\mathrm{G}^{\prime}\right)$ of approximately four times higher and a lower loss modulus $\left(\mathrm{G}^{\prime \prime}\right)$ compared to OPF.
FESEM images of freeze-dried samples (Fig. 4) showed a fairly smooth polymeric surface for OPF, whereas $\mathrm{CaP}$ nanoparticles were observed to be distributed homogeneously throughout the polymeric matrix in case of OPF-CaP samples. Single nanoparticles were clearly recognizable in OPF-CaP hydrogels at high magnification (Fig. 4d). Presence of CaP nanoparticles in OPF-CaP hydrogels was also confirmed by the absorption peaks of apatitic phosphate in ATR-FTIR analysis (Fig. 5).

Fold swelling ratio of OPF and OPF-CaP hydrogels were calculated to be $30.3 \pm 0.6$ and $11.0 \pm 0.2$, respectively. RGD functionalization did not significantly influence the material properties (data not shown).

\section{Cell survival}

Cell survival was assessed 4 and $16 \mathrm{~d}$ after OBLCs encapsulation within the different types of hydrogels. Qualitative data (Fig. 6) at day 4 showed that a majority of live cells (green color) was detected in RGD-containing gels (OPF-R and OPF-R-CaP), whereas an apparent number of dead cells (red color) was identified within RGD-free gels (OPF and OPF-CaP). After $16 \mathrm{~d}$, cell viability was similar for all groups. An additional observation was that OBLCs incorporated in CaP-enriched gels (OPF-CaP and OPF-R-CaP) were homogeneously distributed and isolated from each other compared to cells encapsulated in CaPfree gels (OPF and OPF-R), which appeared as clusters. Quantitative analysis of live cells (Fig. 7) after $4 \mathrm{~d}$ of 


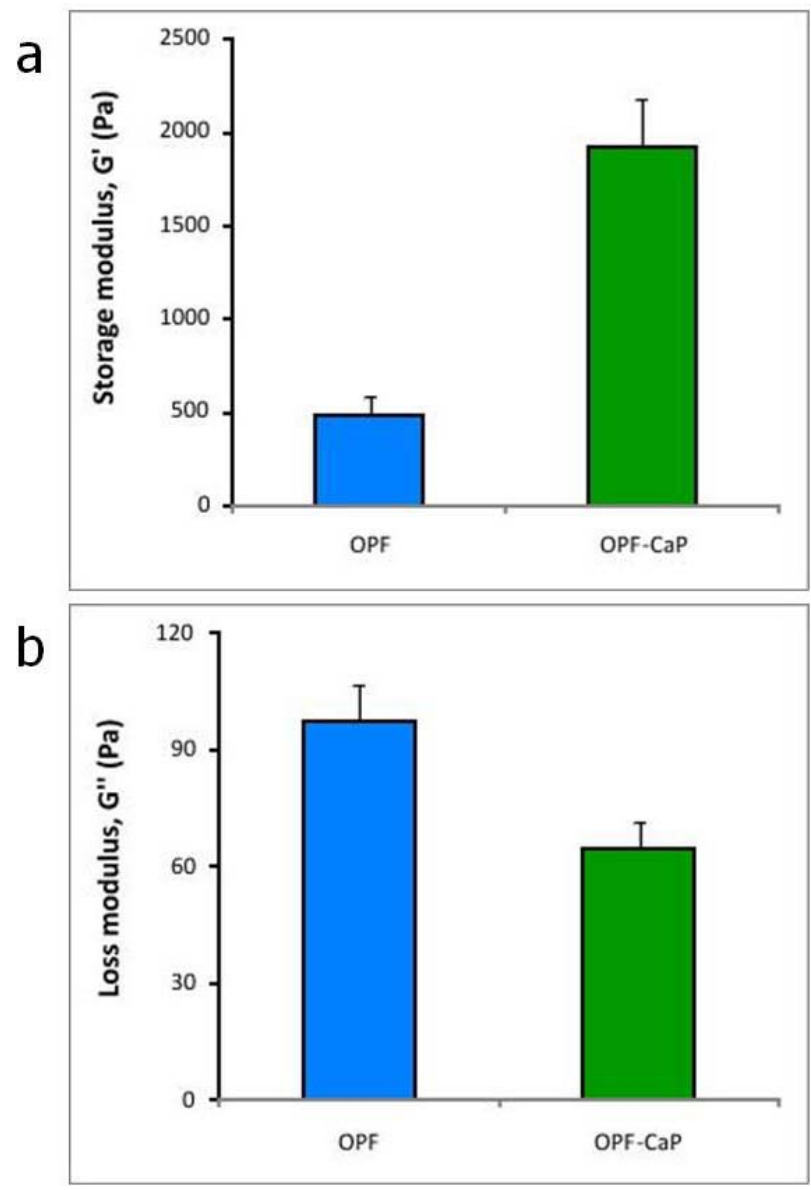

Fig. 3. (a) Storage modulus $\left(\mathrm{G}^{\prime}\right)$ and (b) loss modulus $\left(\mathrm{G}^{\prime \prime}\right)$ of OPF and OPF-CaP hydrogels. Error bars represent means \pm standard deviation.

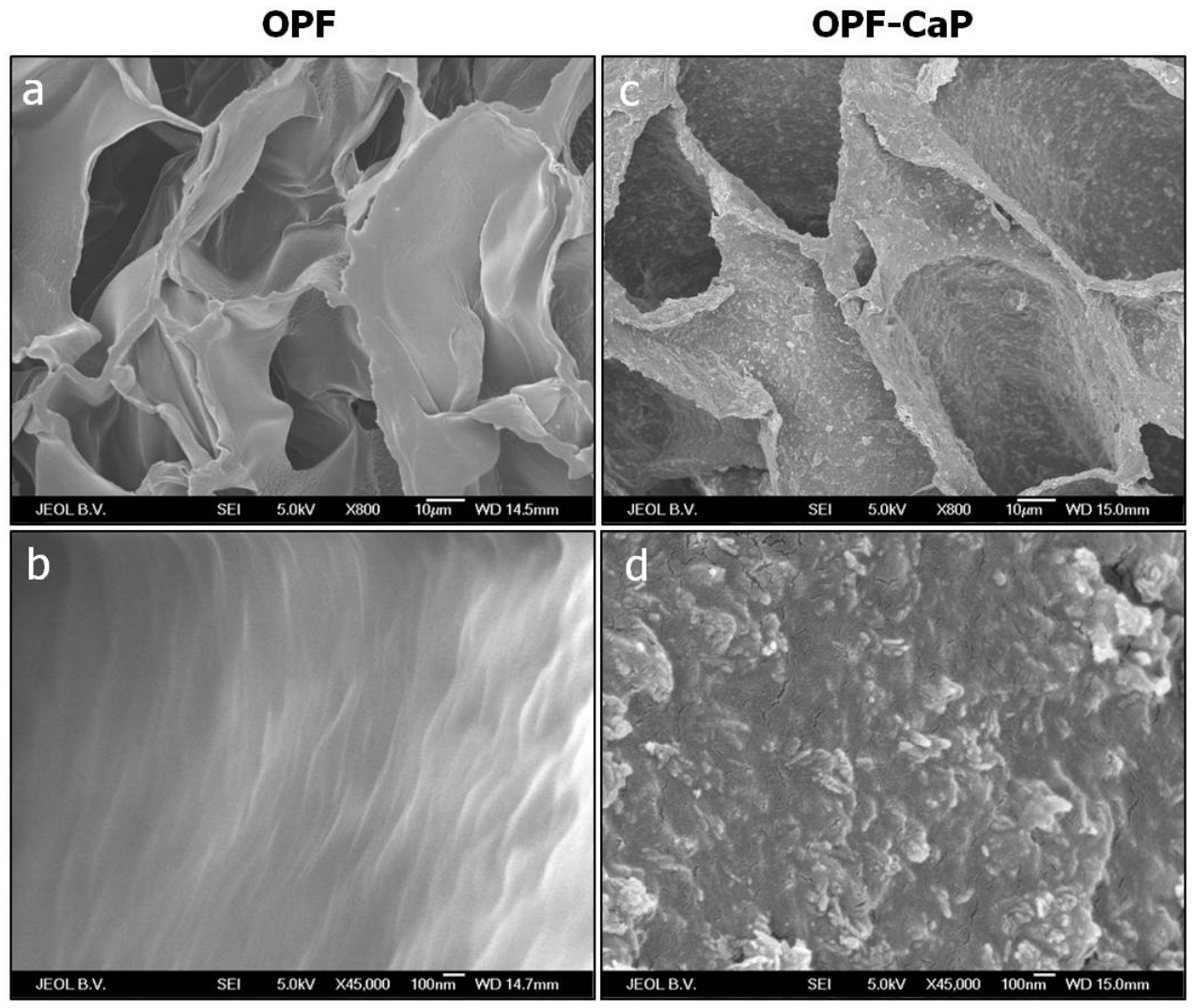

Fig. 4. FESEM images of (a,b) freeze-dried OPF and (c,d) OPF-CaP hydrogels. 

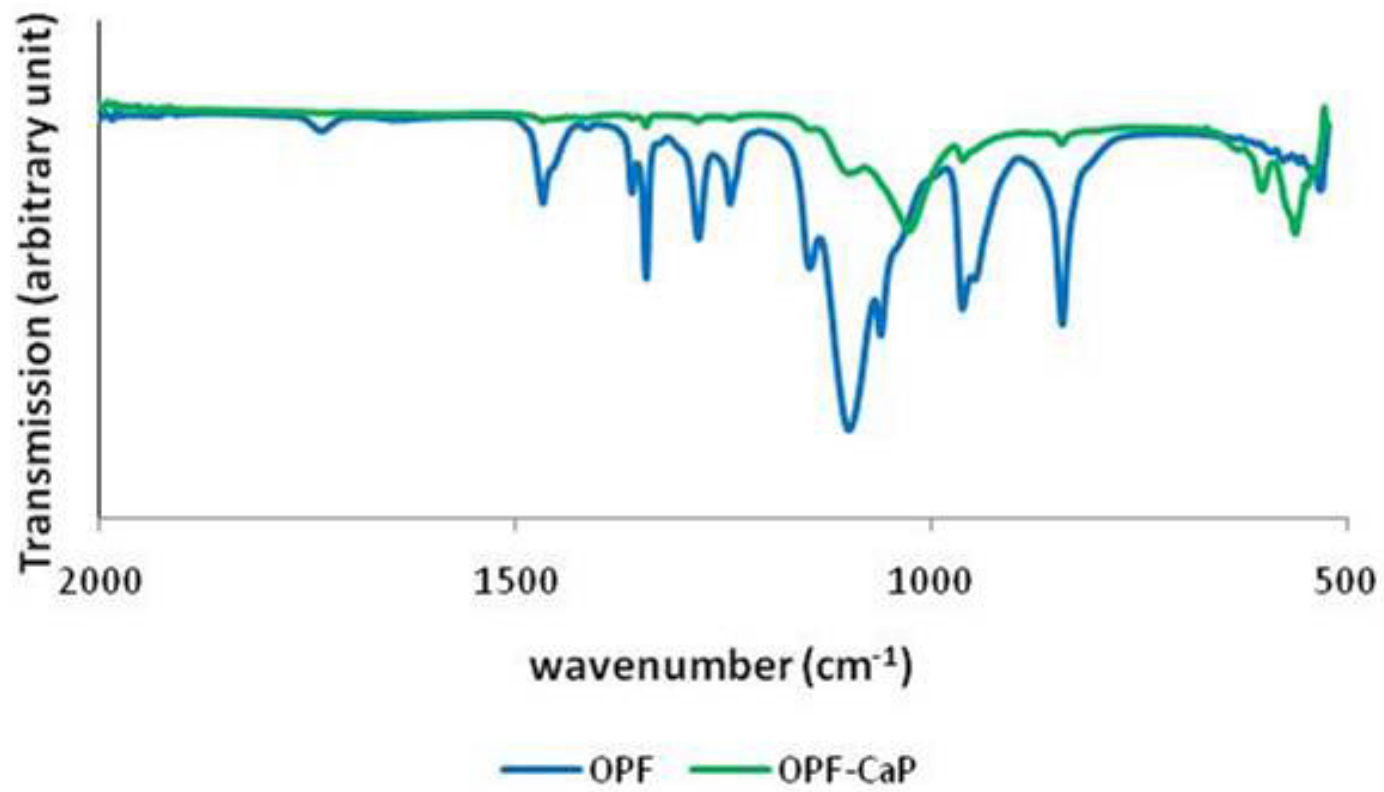

Fig. 5. ATR-FTIR analysis of freeze dried OPF and OPF-CaP hydrogels.

culture showed that $81 \%$ and $92 \%$ of cells were viable in RGD-containing gels (OPF-R and OPF-R-CaP), whereas the percentage of viable cells was reduced to $32 \%$ and 46 $\%$ in RGD-free gels (OPF and OPF-CaP), respectively. By day 16 , the percentage of live cells showed similar values of over $90 \%$ for all experimental groups.

\section{Cell behavior}

Proliferation assay showed a significant decrease in DNA content for CaP-free gels (OPF and OPF-R). On the other hand, DNA content in CaP-enriched gels (OPF-CaP and OPF-R-CaP) remained approximately constant during the culture period (Fig. 8a).

ALP-activity measurements revealed a significant continuous increase for $\mathrm{CaP}$-free gels until day 12 and a decline thereafter. On the contrary, OBLCs encapsulated in CaP-enriched gels showed a minimal ALP-activity until day 12, and an increase thereafter (Fig. 8b).

No significant change in calcium content for $\mathrm{CaP}$ free gels was observed over the entire culture period. In contrast, a drastic increase in calcium deposition was observed for both CaP-enriched gels at days 16 and 24 compared to the earlier time points (Fig. 9a) and to the corresponding cell-free hydrogels, the calcium levels of which increased only gradually during the entire period of soaking in osteogenic medium (Fig. 9b).

Fig. 6. Cell survival in OPF hydrogels 4 and $16 \mathrm{~d}$ after encapsulation by LIVE/DEAD assay. Confocal imaging was utilized to visualize the distribution of live cells in green and the nucleus of dead cells in red in (a,b) OPF, (c,d) OPF-R, (e,f) OPF-CaP, and (g,h) OPF-R-CaP, respectively. (Scale bar $=100 \mu \mathrm{m})$.
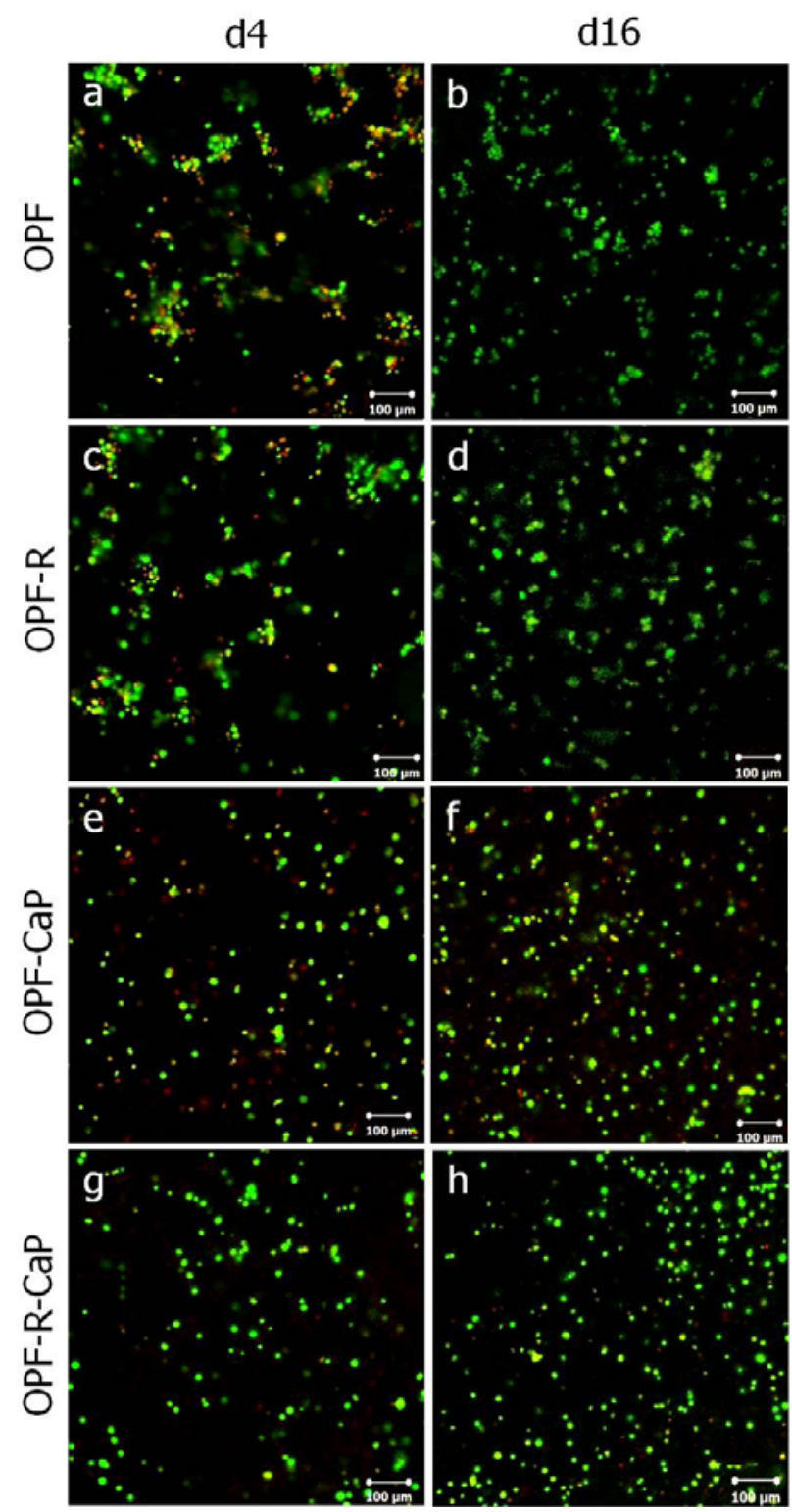


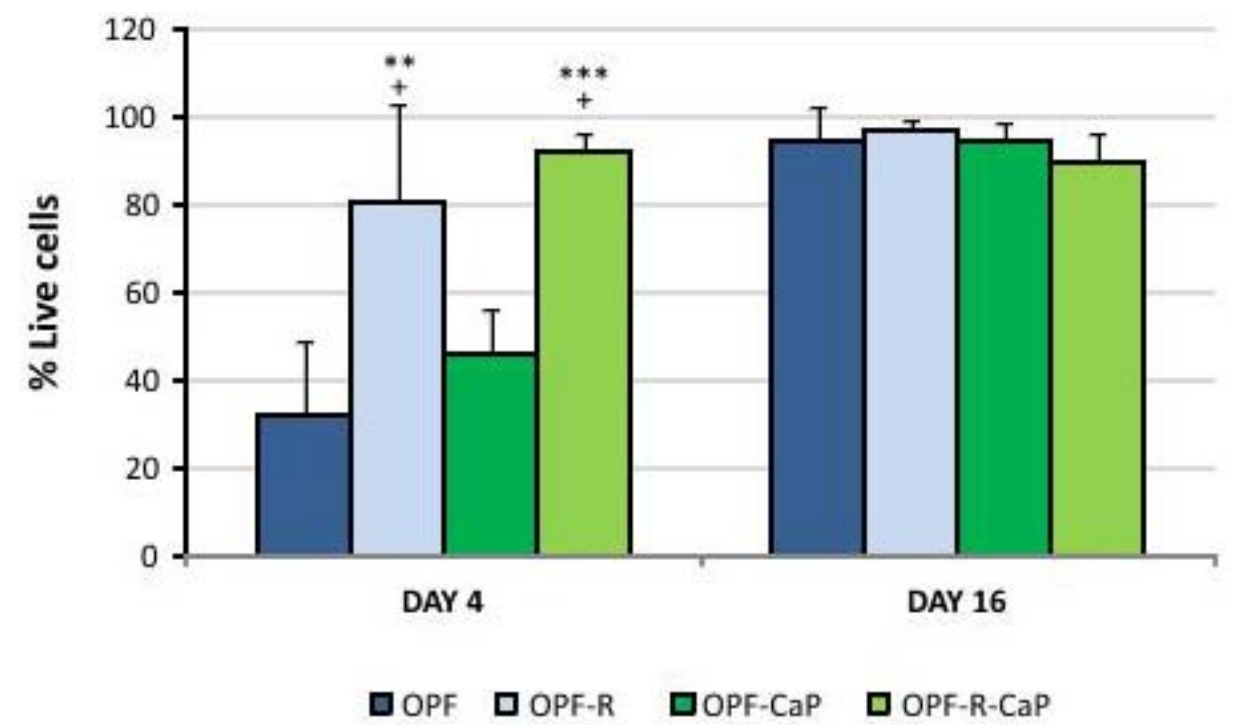

Fig. 7. Quantitative viability analysis of OBLCs in OPF hydrogels after 4 and $16 \mathrm{~d}$. Series of LIVE/DEAD images for each treatment were quantified using ImageJ. $* * p<0.01$ and $* * * p<0.001$ relative to OPF hydrogels. $+p<$ 0.05 relative to OPF-CaP hydrogels. Error bars represent means \pm standard deviation.
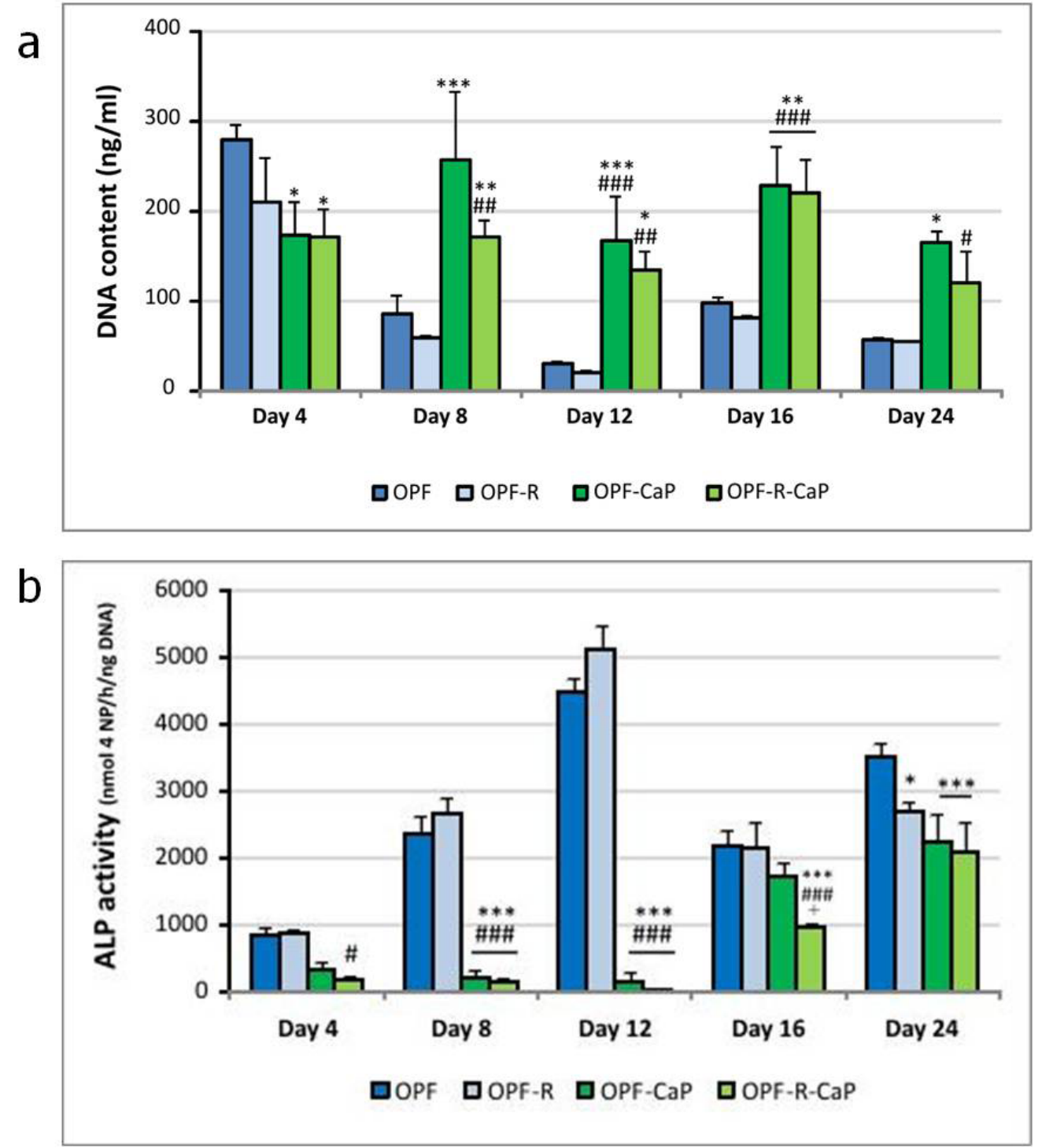

Fig. 8. (a) Proliferation and (b) ALP activity per sample for OBLCs in OPF constructs at different time points of culture. ${ }^{*} p<0.05, * * p<0.01$ and $* * * p<0.001$ relative to OPF hydrogels. \# $p<0.05, \# \# p<0.01$ and \#\#\#p< 0.001 relative to OPF-R hydrogels. $+p<0.05$ relative to OPF-CaP hydrogels. Error bars represent means \pm standard deviation. 

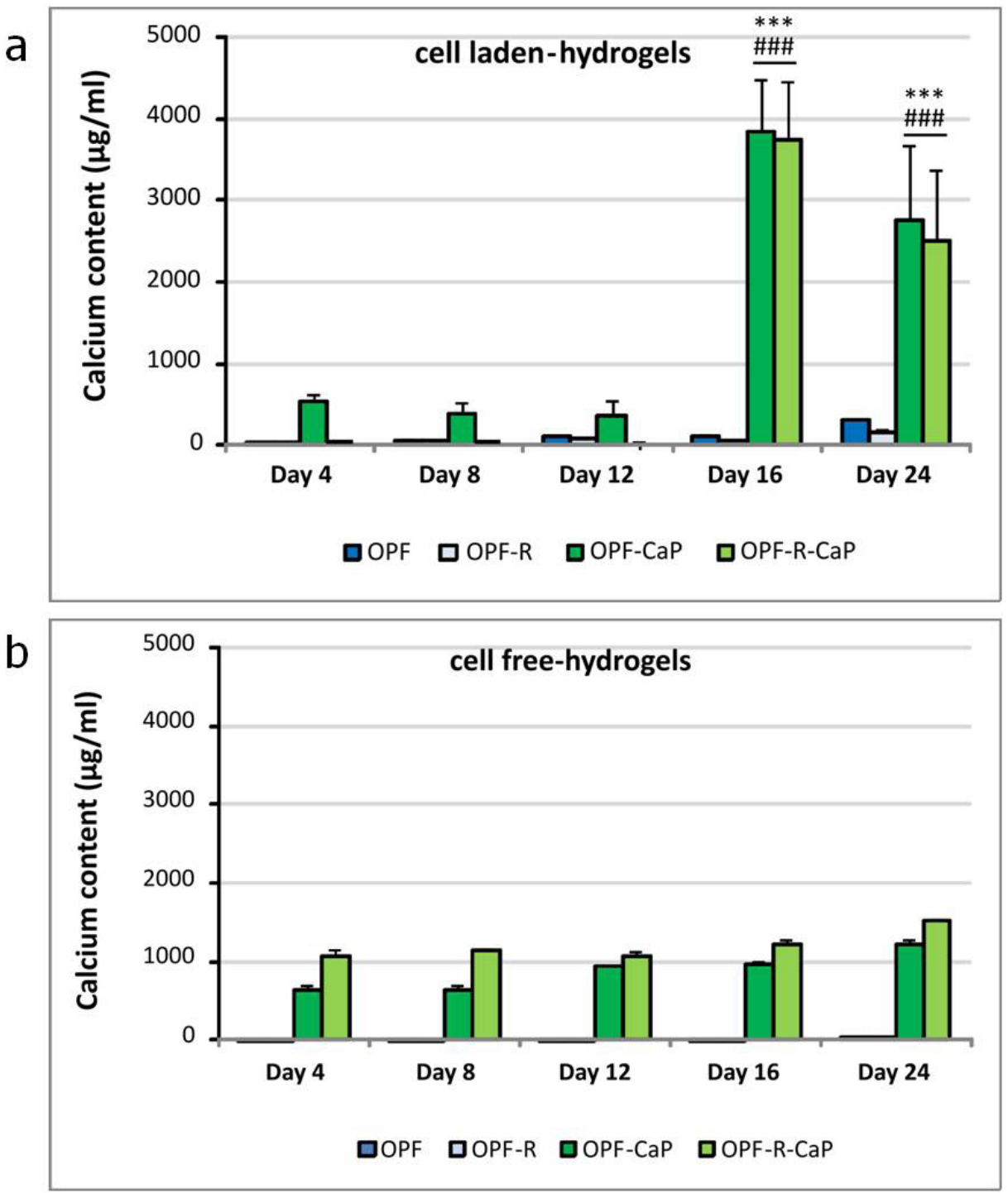

Fig. 9. Calcium content per sample for OBLCs in (a) cell-laden hydrogels and (b) cell-free hydrogels at different time points of culture. ${ }^{* * *} p<0.001$ relative to OPF hydrogels. \#\#\# $p<0.001$ relative to OPF-R hydrogels. Error bars represent means \pm standard deviation.

\section{Cytological Analysis}

Von Kossa-stained histological sections of cell-laden and cell-free hydrogels after 4 and $24 \mathrm{~d}$ of in vitro culture are shown in Fig. 10 and Fig. 11, respectively. This staining technique detects phosphate, and hence calcium phosphate deposits, by using a silver nitrate solution which results in a brown to black stain. For the cell-laden gels, no mineral deposits were found in CaP-free gels (OPF and OPF-R hydrogels) at day 4 (Fig. 10a,c), whereas mineral deposits increased markedly up to $24 \mathrm{~d}$ (Fig. 10b,d). As expected, high mineral content was present in the hydrogels containing CaP nanoparticles (OPF-CaP and OPF-R-CaP), with no qualitative differences between the time points (Fig. 10e-h).

\section{Roundness}

A morphological observation of OBLCs encapsulated within the different types of hydrogels was analyzed to detect cell spreading (Fig. 12). Cell spreading was clearly observed after various culture periods in RGDmodified hydrogel (OPF-R) and apparently less in all other hydrogels. Quantitative determination of cell spreading was performed by calculating the roundness index of cells in two-dimensional morphology and is presented in Fig. 13. The histogram shows a statistically significant higher degree of cell spreading for OBLCs in OPF-R (roundness index $\sim 2$ ) compared to the cells in the other groups (roundness index $\sim 1$ ).

\section{Discussion}

The overall objective of this study was to evaluate the respective effects of adhesive cues, nano-sized $\mathrm{CaP}$ particles and their combination within OPF-based hydrogels on the viability, spreading and osteogenic 

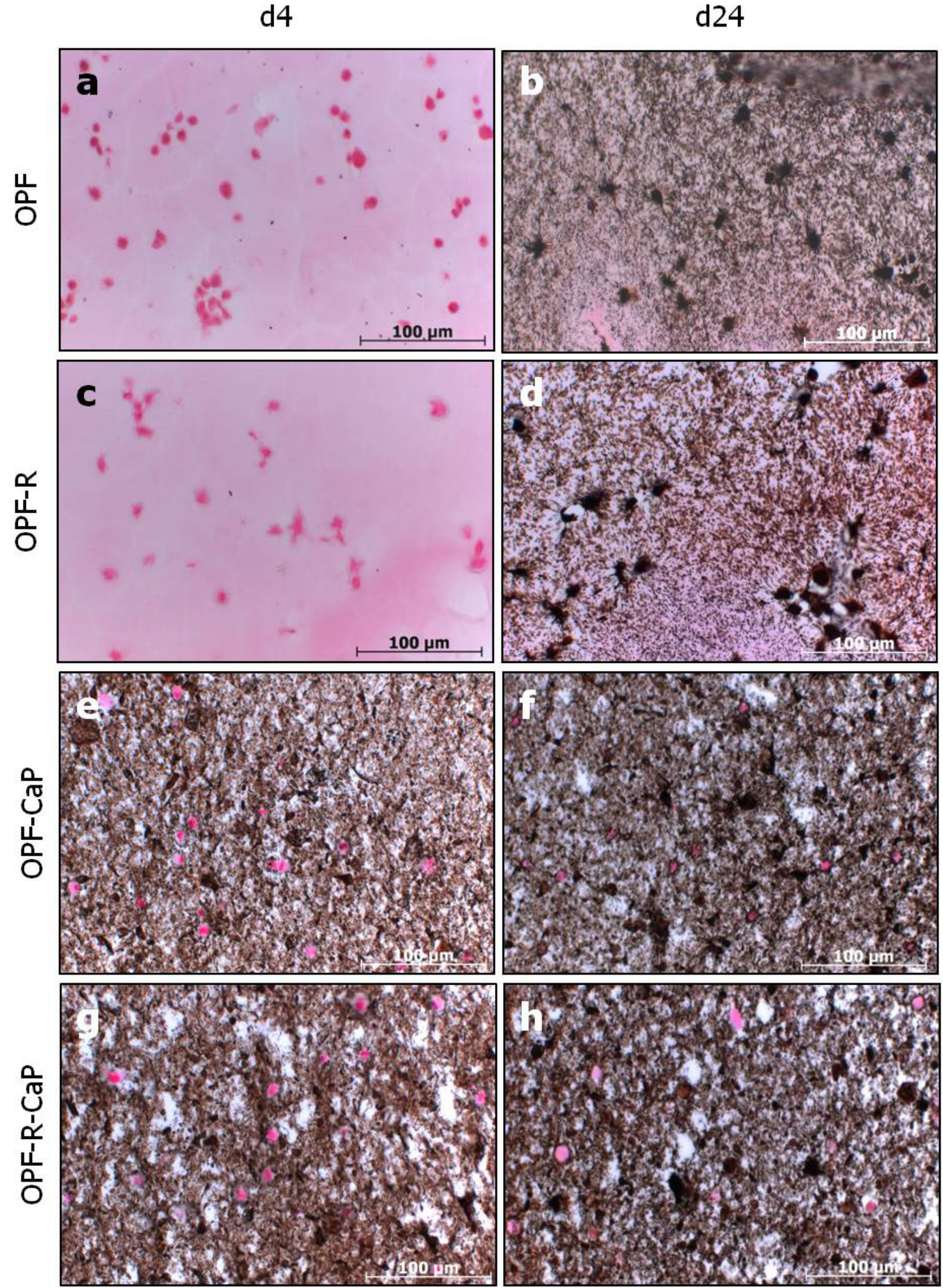

Fig. 10. Von Kossa-stained histological sections $(6 \mu \mathrm{m})$ after 4 and $24 \mathrm{~d}$ in vitro culture of cell-laden OPF hydrogels. Black/brown dots represent the mineral deposition. $($ Scale bar $=100 \mu \mathrm{m})$. 

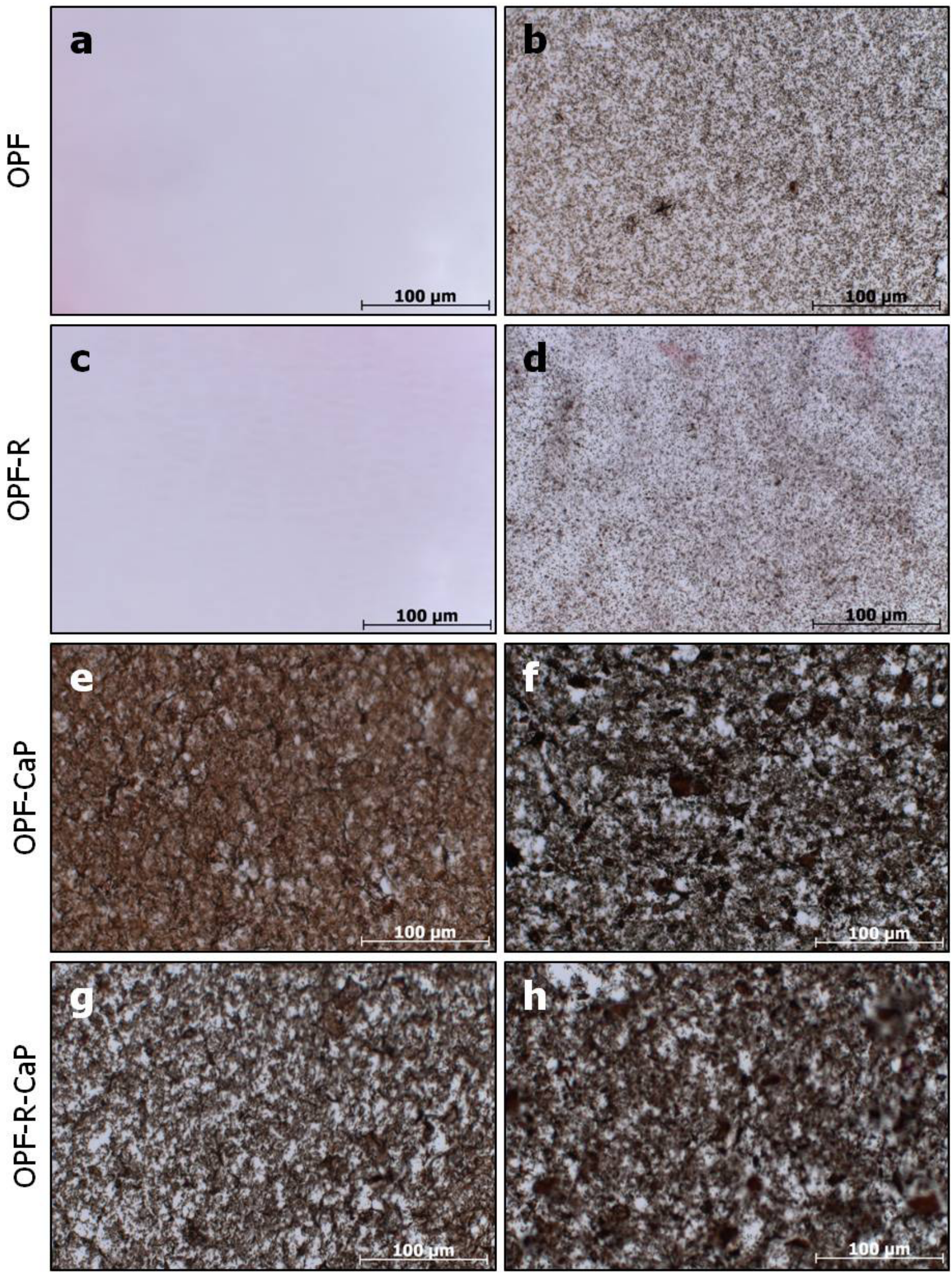

Fig. 11. Von Kossa-stained histological sections $(6 \mu \mathrm{m})$ of cell-free OPF hydrogels after 4 and $24 \mathrm{~d}$ soaked in osteogenic medium. Black/brown dots represent the mineral deposition. (Scale bar $=100 \mu \mathrm{m})$. 


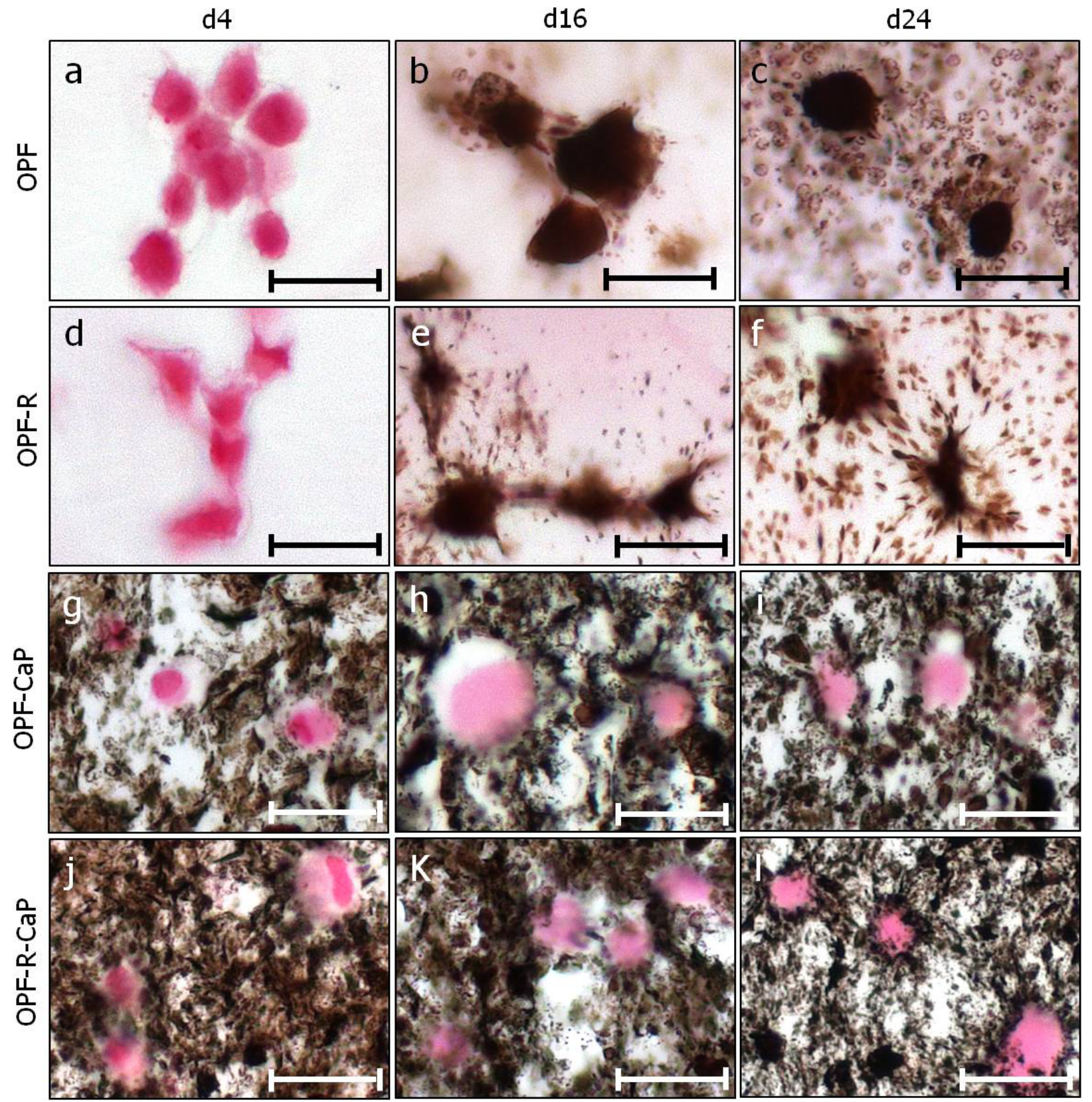

Fig. 12. Cell morphology analyzed with light microscopy of Von Kossa-stained paraffin sections of OBLCs encapsulated in OPF (a-c), OPF-R (d-f), OPF-CaP (g-i), and OPF-R-CaP (j-l) hydrogels at day 4, 16 and 24 of culture. (Scale bar $=20 \mu \mathrm{m})$.

behavior of encapsulated rat bone marrow derived OBLCs. We hypothesized that (i) the interaction of the biomaterial with cells or the presence of CaP nanoparticles contributes to improve cell behavior, and (ii) the combination of these two biomimetic cues increases the osteogenic capacity of cells encapsulated within these synthetic scaffolds even more. Data presented in this study indicate that RGD peptides supported cell spreading and viability, whereas CaP nanoparticles remarkably affected cellmediated hydrogel mineralization, suggesting a potential enhancement of cell differentiation into the osteogenic lineage. More interestingly, RGD peptides and $\mathrm{CaP}$ nanoparticles together sustained both cell survival and formation of mineralized matrix.

\section{RGD peptides}

Synthetic hydrogels have emerged as promising candidate materials for cell encapsulation, owing to their biocompatibility and tailorable properties (Silva and Mooney, 2004). However, the lack of cell-material interactions limit their application to the field of tissue engineering (Drumheller and Hubbell, 1994; Nuttelman et al., 2005). Previous research showed that the incorporation of adhesive cues provides integrin-binding sites for adhesion of cells to the synthetic polymers (Behravesh and Mikos, 2003; Burdick and Anseth, 2002; Nuttelman et al., 2005; Shin et al., 2002). In this work, OPF hydrogels modified with RGD peptides were able to enhance cell viability during the early stages of culture as a consequence 


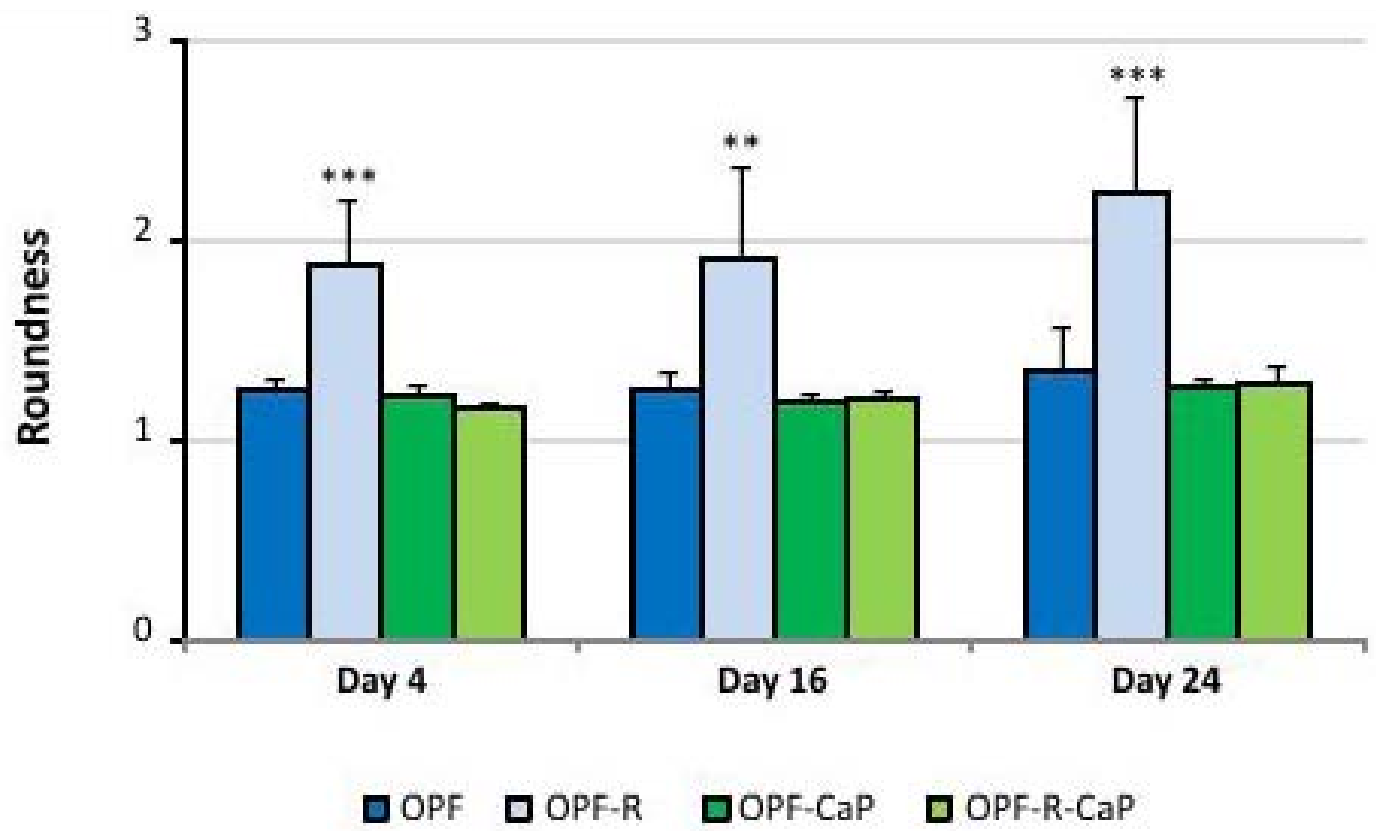

Fig. 13. Quantitative determination of cell morphology by roundness index measurement of OBLCs in OPF hydrogels. Roundness index was calculated by using imaging software analysis. $* * p<0.01$ and $* * * p<0.001$ relative to OPF hydrogels.

of improved cell-material interactions. A limitation of the present study was that we were not able to perform actin and vinculin immunostaining to visualize and to quantify morphological changes, such as cell spreading, elongation, and focal adhesion sites, both in 3D matrices and paraffin embedded-hydrogel sections. Specifically, the red (actin) and green (vinculin) fluorescence dyes were found to result in non-specific staining, most likely due to the limited access of the antibodies to the encapsulated cells in 3D composites. Additionally, the intrinsic autofluorescence of paraffin-embedded OPF sections, acquired during the fixation process, made fluorescent staining unsuitable. Nevertheless, qualitative observation of morphological changes and measurement of cell roundness index on 2D Von Kossa-stained sections clearly showed that RGD peptides allowed cell spreading more than in plain OPF at all time points. Although RGD peptides showed a significant effect on OBLC viability during the early stages of culture, as shown by the high percentage of live cells out of the total number (sum of live and dead cells) present in the scaffolds, cells were unable to proliferate both in peptide-modified and unmodified OPF hydrogels. Indeed, DNA content, which is related to the number of cells present in the hydrogels, decreased over time indicating both a lack of proliferation and cell loss from the scaffolds. Taken together, these data provided indication that although no proliferation and cell loss from the scaffolds occurred over time, the vast majority of cells that remained encapsulated were alive. Our findings are partly consistent with previously reported data by Burdick and Anseth (2002), who showed that RGD peptides failed to promote not only proliferation but also viability of encapsulated rat osteoblasts in a 3D PEG hydrogel network. In contrast, in a more recent publication, Anderson et al. (2011) claimed that proliferation of encapsulated human mesenchymal stem cells (MSCs) occurred in a peptide-functionalized PEG hydrogel. Considering the role of RGD peptides to support cell viability, RGD-free hydrogels showed a lower number of live cells at day 4 of culture. However, this result was in contradiction with the amount of DNA measured in the corresponding groups through the proliferation assay. This conflicting observation might be explained by the interference of DNA released from dead cells that, since it could not be washed out prior to the analysis, was detected together with the DNA of living cells.

ALP activity is considered to be an indicator of early osteogenic differentiation (Lecoeur and Ouhayoun, 1997). In this experiment, RGD-modified OPF hydrogels showed increased ALP activity reaching significantly elevated levels by day 12 . It has been extensively demonstrated that the expression of ALP occurs immediately after the proliferative period (Stein et al., 1990), therefore our data are consistent with the inverse relationship between the proliferation and differentiation rates of BMSc during osteoblast development (Lian and Stein, 1992).

Measurement of calcium content, a late marker for osteogenic differentiation (Lian and Stein, 1992), and qualitative evidence of mineralized matrix production from Von Kossa-stained sections confirmed the ability of cells encapsulated in OPF hydrogels to mineralize (Temenoff et al., 2004b). However, the levels of mineralization were negligible compared to mineralization in CaP-enriched gels for the reasons that will be discussed in the next paragraph. 


\section{CaP nanoparticles}

$\mathrm{CaP}$ nanoparticles, homogeneously dispersed throughout the hydrated hydrogel matrix, were used to mimic the mineralized matrix of bone tissue, thereby creating a biomimetic environment with an instructive capacity for osteogenic differentiation of OBLCs. Here, we demonstrated that $\mathrm{CaP}$ nanoparticles created a biocompatible environment, which allowed for cell survival. A recently published study showed that human bone MSCs, homogeneously distributed within hydrogelbiphasic calcium phosphate (BCP) particle composites, remained morphologically round and isolated from each other through the entire culture period (Sohier et al., 2010). Similarly, in our study qualitative analysis of cell viability confirmed the inability of cells to come in close contact with each other and to form cell-cell interactions, owing to the encumbrance of CaP nanoparticles.

Previous work demonstrated that ALP activity of human osteoblasts decreases in response to high calcium concentrations (Xynos et al., 2000; Haimi et al., 2009). Ohgushi et al. (1993) observed lower ALP expression level at 1 week in HA-enriched polymer materials and a peak in expression level only at 2 weeks. Our results corroborated these reports showing low ALP activity in CaP-enriched hydrogels.

Phosphate-containing molecules incorporated into biomaterial scaffolds have been shown to play a pivotal role in promoting cellular formation of mineral deposits (Murphy and Mooney, 2002; Nuttelman et al., 2006). Similarly, in the present study, large amounts of calcium were measured at later stages of culture in $\mathrm{CaP}$-enriched hydrogels, confirming the effectiveness of CaP nanoparticles to induce cell-mediated production of mineralized matrix. Attempts to detect immunohistochemically osteopontin (OPN) and pro-collagen within the synthetic mineralized matrices have been conducted to reinforce the evidence for cell differentiation along the osteogenic pathway. However, the interference of the $\mathrm{CaP}$ nanoparticles with the corresponding antigens resulted in non-specific staining, and further analyses need to be performed to identify key elements that validate this statement. Although negligible compared to $\mathrm{CaP}$-enriched scaffolds, calcium content and mineral deposits have been detected at a later stage in $\mathrm{CaP}$-free hydrogels by the calcium assay and Von Kossa staining, respectively. The remarkable stimulation of cellmediated mineralization by hydroxyapatite nanoparticles justifies three main conclusions. First, CaP nanoparticles likely enhance cell differentiation along the osteogenic pathway, which corroborates earlier findings by Patel et al. (2010). Second, the presence of highly dispersed $\mathrm{CaP}$ nanoparticles of high specific surface area provided abundant nucleation sites for further mineralization, whereas these nucleation sites for homologous CaP-on$\mathrm{CaP}$ deposition were not available for mineral deposition by cells encapsulated in CaP-free hydrogels. Consequently, deposition of mineralized matrix was considerably accelerated in the presence of $\mathrm{CaP}$ nanoparticles. Third, Engler et al. (2006) proved that the mechanical properties of the hydrogels strongly influence cell behavior. Specifically, rigid hydrogels of high stiffness that mimic the mineralized ECM of bone would guide naive MSCs towards the osteogenic lineage. Accordingly, in the present study, the higher rigidity of CaP-enriched hydrogels (as confirmed by our rheological characterization) would stimulate differentiation of OBLCs encapsulated in these hydrogels.

In a recent study in our laboratory, it was observed that acellular CaP-containing OPF hydrogels mineralized in vitro, thus confirming the capacity of these hydrogels to act as templates for calcification. However, the degree of acellular mineralization was substantially lower than the amount of cellular mineralization (which was already compensated for acellular mineralization by subtracting the values obtained for cell-free blanks). Thus, the increase of calcium deposition observed in the respective cell ladenconstructs was undoubtedly the result of cellular activity. Furthermore, a small amount of mineral deposits formed even in CaP-free OPF samples.

Combined effect of RGD peptides and CaPnanoparticles As hypothesized, the tethered cell adhesion ligands and incorporated $\mathrm{CaP}$ nanoparticles within the OPF hydrogels promoted both cell survival and biomineralization, although we could not rule out a synergistic effect of the two components. Specifically, the percentage of live cells in OPF-R-CaP hydrogels was significantly greater compared to OPF-CaP at initial stages of culture, confirming the crucial role of RGD to guarantee cell survival in these hydrogel composite systems. However, differently from OPF-R hydrogels, cells encapsulated in OPF-R-CaP showed a rounded morphology at all time points. An explanation for our observation is that most RGD peptides adsorbed onto the $\mathrm{CaP}$ nanoparticles thus resulting in the lack of interaction between the functionalized matrix and the entrapped cells which, however, remained alive as observed by cell viability. Otherwise, even though RGD peptides could be available for the cells, the small mesh size of cross-linked networks coupled with the presence of $\mathrm{CaP}$ nanoparticles, that considerably reduced hydrogel swelling, might have restricted spreading of encapsulated cells. In either case, our results are consistent with previous findings showing that cell spreading is not a crucial event for osteogenesis, as osteogenic differentiation occurred while cells maintained a round morphology in 3D PEG hydrogel systems (Benoit et al., 2008). Moreover, in that same report and in others (Grzesik and Robey, 1994; Sawyer et al., 2005; Sawyer et al., 2007), the authors claimed the arguable role of synthetic RGD peptide in modulating cell adhesion to biomaterials when presented within a context of adsorbed integrin-binding proteins, either present in the serum or secreted by the cells, thereby decreasing the efficacy of the incorporated RGD.

In conclusion, this study demonstrated that material properties and appropriate selection of instructive cues are the key challenge for well-defined engineered extracellular environments that are able to regulate cell functions. Specifically, RGD peptide sequences were involved in cell spreading and cell survival in the synthetic ECM, whereas CaP nanoparticles seemed to have a stimulatory effect on cell differentiation by mimicking the inorganic compounds of natural bone. However, further analyses need to be conducted to confirm this finding. Ultimately, the combined effect of RGD peptides and $\mathrm{CaP}$ nanoparticles 
increased the overall biological performance of the scaffolds by modulating both cell survival and production of mineralized matrix by encapsulated OBLCs. This stimulus for mineral nucleation by encapsulated OBLCs within synthetic materials can have profound implications for bone tissue engineering strategies.

\section{Acknowledgements}

The authors are grateful to Richard Thibault (Department of Bioengineering, Rice University, Houston, Texas, USA) for assistance with cell isolations.

\section{References}

Anderson SB, Lin CC, Kuntzler DV, Anseth KS (2011) The performance of human mesenchymal stem cells encapsulated in cell-degradable polymer-peptide hydrogels. Biomaterials 32: 3564-3574.

Barczyk M, Carracedo S, Gullberg D (2010) Integrins. Cell Tissue Res 339: 269-280.

Behravesh E, Mikos AG (2003) Three-dimensional culture of differentiating marrow stromal osteoblasts in biomimetic poly(propylene fumarate-co-ethylene glycol)based macroporous hydrogels. J Biomed Mater Res A 66A: 698-706.

Bellis SL (2011) Advantages of RGD peptides for directing cell association with biomaterials. Biomaterials 32: 4205-4210.

Benoit DSW, Schwartz MP, Durney AR, Anseth KS (2008) Small functional groups for controlled differentiation of hydrogel-encapsulated human mesenchymal stem cells. Nat Mater 7: 816-823.

Bongio M, van den Beucken JJJP, Leeuwenburgh SCG, Jansen JA (2010) Development of bone substitute materials: from 'biocompatible' to 'instructive'. J Mater Chem 20: 8747-8759.

Brink KS, Yang PJ, Temenoff JS (2009) Degradative properties and cytocompatibility of a mixed-mode hydrogel containing oligo[poly(ethylene glycol) fumarate] and poly(ethylene glycol)dithiol. Acta Biomater 5: 570-579.

Burdick JA, Anseth KS (2002) Photoencapsulation of osteoblasts in injectable RGD-modified PEG hydrogels for bone tissue engineering. Biomaterials 23: 4315-4323.

Drumheller PD, Hubbell JA (1994) Polymer networks with grafted cell-adhesion peptides for highly biospecific cell adhesive substrates. Anal Biochem 222: 380-388.

Drury JL, Mooney DJ (2003) Hydrogels for tissue engineering: scaffold design variables and applications. Biomaterials 24: 4337-4351.

Engler AJ, Sen S, Sweeney HL, Discher DE (2006) Matrix elasticity directs stem cell lineage specification. Cell 126: 677-689.

Grzesik WJ, Robey PG (1994) Bone-matrix RGD glycoproteins - immunolocalization and interaction with human primary osteoblastic bone-cells in-vitro. J Bone Miner Res 9: 487-496.

Guo X, Park H, Young S, Kretlow JD, van den Beucken JJ, Baggett LS, Tabata Y, Kasper FK, Mikos AG, Jansen JA (2010) Repair of osteochondral defects with biodegradable hydrogel composites encapsulating marrow mesenchymal stem cells in a rabbit model. Acta Biomater 6: 39-47.

Haimi S, Moimas L, Pirhonen E, Lindroos B, Huhtala H, Raty S, Kuokkanen H, Sandor GK, Miettinen S, Suuronen R (2009) Calcium phosphate surface treatment of bioactive glass causes a delay in early osteogenic differentiation of adipose stem cells. J Biomed Mater Res A 91A: 540-547.

Hern DL, Hubbell JA (1998) Incorporation of adhesion peptides into nonadhesive hydrogels useful for tissue resurfacing. J Biomed Mater Res 39: 266-276.

Holland TA, Tabata Y, Mikos AG (2003) In vitro release of transforming growth factor-beta 1 from gelatin microparticles encapsulated in biodegradable, injectable oligo(poly(ethylene glycol) fumarate) hydrogels. J Control Release 91: 299-313.

Holland TA, Bodde EWH, Baggett LS, Tabata Y, Mikos AG, Jansen JA (2005) Osteochondral repair in the rabbit model utilizing bilayered, degradable oligo(poly(ethylene glycol) fumarate) hydrogel scaffolds. J Biomed Mater Res A 75A: 156-167.

Jo S, Shin H, Mikos AG (2001a) Modification of oligo(poly(ethylene glycol) fumarate) macromer with a GRGD peptide for the preparation of functionalized polymer networks. Biomacromolecules 2: 255-261.

Jo S, Shin H, Shung AK, Fisher JP, Mikos AG (2001b) Synthesis and characterization of oligo(poly(ethylene glycol) fumarate) macromer. Macromolecules 34: 28392844.

Kilpadi KL, Chang PL, Bellis SL(2001) Hydroxylapatite binds more serum proteins, purified integrins, and osteoblast precursor cells than titanium or steel. J Biomed Mater Res 57: 258-267.

Kim J, Kim IS, Cho TH, Kim HC, Yoon SJ, Choi J, Park Y, Sun K, Hwang SJ (2010) In vivo evaluation of MMP sensitive high-molecular weight HA-based hydrogels for bone tissue engineering. J Biomed Mater Res A 95: 673681.

Lecoeur L, Ouhayoun JP (1997) In vitro induction of osteogenic differentiation from non-osteogenic mesenchymal cells. Biomaterials 18: 989-993.

Leeuwenburgh SCG, Jansen JA, Mikos AG (2007) Functionalization of oligo(poly(ethylene glycol)fumarate) hydrogels with finely dispersed calcium phosphate nanocrystals for bone-substituting purposes. J Biomater Sci-Polym Ed 18: 1547-1564.

Lian JB, Stein GS (1992) Concepts of osteoblast growth and differentiation - basis for modulation of bone cell-development and tissue formation. Crit Rev Oral Bio Med 3: 269-305.

Murphy WL, Mooney DJ (2002) Bioinspired growth of crystalline carbonate apatite on biodegradable polymer substrata. J Am Chem Soc 124: 1910-1917.

Nuttelman CR, Tripodi MC, Anseth KS (2005) Synthetic hydrogel niches that promote hMSC viability. Matrix Biol 24: 208-218.

Nuttelman CR, Benoit DSW, Tripodi MC, Anseth KS (2006) The effect of ethylene glycol methacrylate phosphate in PEG hydrogels on mineralization and viability of encapsulated hMSCs. Biomaterials 27: 13771386. 
Ohgushi H, Dohi Y, Tamai S, Tabata S (1993) Osteogenic differentiation of marrow stromal stem-cells in porous hydroxyapatite ceramics. J Biomed Mater Res 27: 1401-1407.

Park H, Temenoff JS, Holland TA, Tabata Y, Mikos AG (2005) Delivery of TGF-beta 1 and chondrocytes via injectable, biodegradable hydrogels for cartilage tissue engineering applications. Biomaterials 26: 7095-7103.

Park H, Temenoff JS, Tabata Y, Caplan AI, Mikos AG (2007) Injectable biodegradable hydrogel composites for rabbit marrow mesenchymal stem cell and growth factor delivery for cartilage tissue engineering. Biomaterials 28: 3217-3227.

Patel M, Patel KJ, Caccamese JF, Coletti DP, Sauk JJ, Fisher JP (2010) Characterization of cyclic acetal hydroxyapatite nanocomposites for craniofacial tissue engineering. J Biomed Mater Res A 94A: 408-418.

Paxton JZ, Donnelly K, Keatch RP, Baar K (2009) Engineering the bone-ligament interface using polyethylene glycol diacrylate incorporated with hydroxyapatite. Tissue Eng A 15: 1201-1209.

Peppas NA, Hilt JZ, Khademhosseini A, Langer R (2006) Hydrogels in biology and medicine: From molecular principles to bionanotechnology. Adv Mater 18: $1345-1360$.

Peter SJ, Lu LC, Kim DJ, Mikos AG (2000) Marrow stromal osteoblast function on a poly(propylene fumarate)/ beta-tricalcium phosphate biodegradable orthopaedic composite. Biomaterials 21: 1207-1213.

Pierschbacher MD, Ruoslahti E (1984) Cell attachment activity of fibronectin can be duplicated by small synthetic fragments of the molecule. Nature 309: 30-33.

Salinas CN, Anseth KS (2009) Mesenchymal stem cells for craniofacial tissue regeneration: designing hydrogel delivery vehicles. J Dent Res 88: 681-692.

Sawyer AA, Hennessy KM, Bellis SL (2005) Regulation of mesenchymal stem cell attachment and spreading on hydroxyapatite by RGD peptides and adsorbed serum proteins. Biomaterials 26: 1467-1475.

Sawyer AA, Hennessy KM, Bellis SL (2007) The effect of adsorbed serum proteins, RGD and proteoglycanbinding peptides on the adhesion of mesenchymal stem cells to hydroxyapatite. Biomaterials 28: 383-392.

Shin H, Jo S, Mikos AG (2002) Modulation of marrow stromal osteoblast adhesion on biomimetic oligo[poly(ethylene glycol) fumarate] hydrogels modified with Arg-Gly-Asp peptides and a poly(ethylene glycol) spacer. J Biomed Mater Res 61: 169-179.

Shin H, Ruhe PQ, Mikos AG, Jansen JA (2003) In vivo bone and soft tissue response to injectable, biodegradable oligo(poly(ethylene glycol) fumarate) hydrogels. Biomaterials 24: 3201-3211.

Shin H, Zygourakis K, Farach-Carson MC, Yaszemski MJ, Mikos AG (2004a) Attachment, proliferation, and migration of marrow stromal osteoblasts cultured on biomimetic hydrogels modified with an osteopontinderived peptide. Biomaterials 25: 895-906.

Shin H, Zygourakis K, Farach-Carson MC, Yaszemski MJ, Mikos AG (2004b) Modulation of differentiation and mineralization of marrow stromal cells cultured on biomimetic hydrogels modified with Arg-Gly-Asp containing peptides. J Biomed Mater Res A 69A: 535-543.

Shin H, Temenoff JS, Bowden GC, Zygourakis K, Farach-Carson MC, Yaszemski MJ, Mikos AG (2005) Osteogenic differentiation of rat bone marrow stromal cells cultured on Arg-Gly-Asp modified hydrogels without dexamethasone and beta-glycerol phosphate. Biomaterials 26: 3645-3654.

Silva EA, Mooney DJ (2004) Synthetic extracellular matrices for tissue engineering and regeneration. Curr Top Dev Biol 64: 181-205.

Sohier J, Corre P, Weiss P, Layrolle P (2010) Hydrogel/ calcium phosphate composites require specific properties for three-dimensional culture of human bone mesenchymal cells. Acta Biomater 6: 2932-2939.

Stein GS, Lian JB, Owen TA (1990) Relationship of cell-growth to the regulation of tissue-specific geneexpression during osteoblast differentiation. FASEB J 4: 3111-3123.

Temenoff JS, Athanasiou KA, Lebaron RG, Mikos AG (2002) Effect of poly(ethylene glycol) molecular weight on tensile and swelling properties of oligo(poly(ethylene glycol) fumarate) hydrogels for cartilage tissue engineering. J Biomed Mater Res 59: 429-437.

Temenoff JS, Park H, Jabbari E, Conway DE, Sheffield TL, Ambrose CG, Mikos AG (2004a) Thermally crosslinked oligo(poly(ethylene glycol) fumarate) hydrogels support osteogenic differentiation of encapsulated marrow stromal cells in vitro. Biomacromolecules 5: 5-10.

Temenoff JS, Park H, Jabbari E, Sheffield TL, Lebaron $\mathrm{RG}$, Ambrose CG, Mikos AG (2004b) In vitro osteogenic differentiation of marrow stromal cells encapsulated in biodegradable hydrogels. J Biomed Mater Res A 70A: 235-244.

$\mathrm{Xu}$ WJ, Ma JY, Jabbari E (2010) Material properties and osteogenic differentiation of marrow stromal cells on fiber-reinforced laminated hydrogel nanocomposites. Acta Biomater 6: 1992-2002.

Xynos ID, Hukkanen MVJ, Batten JJ, Buttery LD, Hench LL, Polak JM (2000) Bioglass (R) 45S5 stimulates osteoblast turnover and enhances bone formation in vitro: Implications and applications for bone tissue engineering. Calcif Tissue Int 67: 321-329.

\section{Discussion with Reviewers}

Reviewer II: It would be interesting to know 1) whether the increase in Ca could be due to the presence of mineralizing proteins from the media, 2) what is the role of RGD in cell viability compared to $\mathrm{RGD}+\mathrm{CaP}$, and 3 ) what is the role of $\mathrm{CaP}$ in hydrogel mineralization compared to RGD+CaP? Authors: 1) Proteins from the media can indeed contribute to mineralization of hydrogels, but it should be noted that a substantial increase in calcium content was only observed for cell-containing hydrogels. Cell-free hydrogel composites, on the other hand, mineralized to a much lesser extent even though they were soaked in fully supplemented osteogenic culture medium containing several proteins. In addition, the level of calcification remained rather constant 
in contrast to the abrupt increase in mineralization at lager stages of culture observed for cell-containing gel composites. These findings clearly demonstrate that the increase in calcium during the later stages of culture was essentially due to cellular activity rather than calcium binding by proteins from the surrounding media. 2) RGD peptides were shown to enhance cell viability during the early stages of culture both in OPF-R and OPF-R-CaP hydrogels. This result suggested that only RGD peptides, and not $\mathrm{CaP}$ nanoparticles, were involved in promoting cell survival, likely due to improved cell-material interactions. 3) $\mathrm{CaP}$ nanoparticles were shown to promote cell-mediated hydrogel mineralization during the later stages of culture, both in OPF-CaP and OPF-R-CaP scaffolds. RGD peptides coupled to $\mathrm{CaP}$ nanoparticles did not show improvement in mineralization compared to $\mathrm{CaP}$ nanoparticles alone. This finding indicates that RGD only plays a crucial role in enhancing cell viability, but does not contribute to increased cell-mediated mineralization.

Reviewer II: Is the roundness experiment (where the measurements are taken from images from only one view) an appropriate method to measure cell spreading of cells growing in 3D?

Authors: Roundness measurement in 3 dimensions (3D) would have been undoubtedly more appropriate in order to obtain accurate qualitative and quantitative information of cell morphological changes. However, as explained in the discussion, vinculin-actin immunostaining in $3 \mathrm{D}$ scaffolds was not feasible to perform most likely due to the limited access of the antibodies to the encapsulated cells. Analysis of cell spreading in 2D paraffin sections was the best solution to measure cell roundness given the experimental conditions of this study.

Reviewer III: This study focuses on one RGD concentration and one polymer:calcium phosphate ratio. Would you expect a different cell behaviour if different concentrations or RGD and/or different polymer:calcium phosphate ratios were used?

Authors: The choice of RGD concentration of $2 \mu \mathrm{mol} / \mathrm{g}$ was based on previous studies by Shin et al. (2004b; 2005), which showed that $0.1 \mu \mathrm{mol} / \mathrm{g}$ had a minimal effect on cell proliferation, ALP activity and mineralization and that 1 $\mu \mathrm{mol} / \mathrm{g}$ did not show any marked difference compared to $2 \mu \mathrm{mol} / \mathrm{g}$. Therefore, we selected $2 \mu \mathrm{mol} / \mathrm{g}$ as the concentration of RGD to obtain a biological effect in the present study. As described in the manuscript, the amount of $\mathrm{CaP}$ in the hydrogels is the maximum amount possible using the described methods. Changing the polymer/ $\mathrm{CaP}$ ratio would influence the mechanical and physical properties of the hydrogels, which in turn might influence the cell behavior. Optimization of the ratios would be very interesting for further studies. 